\title{
The role of anthropogenic aerosols in the anomalous cooling from 1960 to 1990 in the CMIP6 Earth System Models
}

\author{
Jie Zhang ${ }^{1}$, Kalli Furtado ${ }^{2 *}$, Steven T. Turnock ${ }^{2}$, Jane P. Mulcahy ${ }^{2}$, Laura J.Wilcox ${ }^{3}$, \\ Ben B. Booth ${ }^{2}$, David Sexton ${ }^{2}$, Tongwen $\mathrm{Wu}^{1}$, Fang Zhang ${ }^{1}$, Qianxia Liu ${ }^{1}$ \\ ${ }^{1}$ Beijing Climate Center, China Meteorological Administration, Beijing, China, 100081 \\ ${ }^{2}$ Met Office Hadley Centre, Exeter, UK, EX1 3PB \\ ${ }^{3}$ National Centre for Atmospheric Science, Department of Meteorology, University of Reading, \\ Reading, UK \\ Corresponding to: Kalli Furtado (kalli.furtado@metoffice.gov.uk)
}

Abstract The Earth System Models (ESMs) that participated in the $6^{\text {th }}$ Coupled Model Intercomparison Project (CMIP6) tend to simulate excessive cooling in surface air temperature (TAS) between 1960 and 1990. The anomalous cooling is pronounced over the Northern Hemisphere $(\mathrm{NH})$ midlatitudes, coinciding with the rapid growth of anthropogenic sulfur dioxide $\left(\mathrm{SO}_{2}\right)$ emissions, the primary precursor of atmospheric sulphate aerosols. Historical simulations with and without anthropogenic aerosol emissions indicate that the anomalous cooling in the ESMs is partly due to overestimating anthropogenic aerosols and aerosol-forcing sensitivity. Structural uncertainties between ESMs that contribute to these two factors have a larger impact on the anomalous cooling than internal variability. CMIP6 simulations can also help us to quantify the relative contributions of aerosol-forcing-sensitivity by aerosol-radiation interactions (ARI) and by aerosol-cloud interactions (ACI). However, even when the aerosol-forcing-sensitivity is similar between ESMs, the relative contributions of ARI and ACI may be substantially different. The ACI accounts for 64 to $87 \%$ of the aerosol-forcing-sensitivity and is the main source of differences between the ESMs. The ACI can be further decomposed into a cloud-amount term (which depends linearly on cloud fraction) and a cloud-albedo term (which is independent of cloud fraction, to the first order). The large uncertainties of cloud-amount term are responsible for the aerosol-forcing-sensitivity differences and further the anomalous cooling differences among ESMs. The metrics 
used here therefore provide a simple way of assessing the physical mechanisms contributing to anomalous twentieth century cooling in any given ESM, which may benefit future model developments.

\section{Introduction}

Surface air temperature (TAS) variation is an essential indicator of climate change, and reproducing the evolution of historical TAS is a crucial criterion for model evaluation. However, the historical TAS anomaly simulated by the models in the $6^{\text {th }}$ Coupled Model Intercomparison Project (CMIP6) is on average colder than that observed in the mid-twentieth century, whereas the CMIP5 models tracked the instrumental TAS variation quite well (Flynn and Mauritsen, 2020). This is surprising because the transient climate response in CMIP6 models is generally higher than in CMIP5 models (e.g., Flynn and Mauritsen, 2020; Meehl et al., 2020).

As a result of anthropogenic emissions, atmospheric aerosol concentrations increased along with rising greenhouse gases, but with greater decadal variability. Aerosols increased rapidly in the mid-twentieth century, predominantly due to US and European emissions. There has been little change in the global total emissions since 1980, but there has been a shift in emission source regions. European and US emissions have declined following the introduction of clean air legislation, while Asian emissions have risen due to economic development. Although greenhouse warming was concluded to be the dominant forcing for long-term changes (e.g., Weart, 2008; Bindoff et al., 2013), multidecadal variability in TAS and the reduced rate of warming in the mid-twentieth century in particular, has been attributed to aerosol forcing (e.g. Wilcox et al., 2013). Ramanathan and Feng (2009) noted that the aerosol cooling effect might have masked as much as $47 \%$ of the global warming by greenhouse gases in the year 2005 , with an uncertainty range of $20 \sim 80 \%$. The aerosol cooling effect is mainly attributed to the ability of sulphate particles to reflect incoming solar radiation and modify the microphysical properties of clouds (e.g., Charlson et al., 1990; Mitchell et al., 1995; Lohmann and Feichter, 2005). The 
increase in anthropogenic aerosols was also responsible for weakening the hydrological cycle between the 1950s and the 1980s (Wu et al., 2013).

There have been efforts to study the anomalous mid-twentieth century cooling in the CMIP6 models. Flynn and Mauritsen (2020) suggested that aerosol cooling is too strong in many CMIP6 models because there is no apparent relationship between the warming trends simulated by models and their transient climate responses (TCRs) before the 1970s. The warming trend is larger than observed post-1970 in CMIP6 models, offsetting the pre-1970s cooling. Dittus et al. (2020) found that historical simulations can better capture the observed historical record by reducing the aerosol emissions in HadGEM3-GC3.1, demonstrating an overly strong aerosol cooling effect. They showed that simulations with large anthropogenic aerosol emissions had greater cooling trends between 1951 and 1980, which were significantly different to the observed trend, while simulations with smaller aerosol forcing were more consistent with observations.

In this study we characterize the mid-twentieth century excessive cooling in CMIP6 ESMs. In order to quantify the role of aerosol processes in this anomalous cooling, historical experiments with and without anthropogenic aerosol emissions are employed. The remainder of the paper is organized as follows. Section 2 introduces the models, data, and a quantitative method to separate the aerosol forcing components. The major features of anomalous cooling in CMIP6 ESMs are examined in section 3. Section 4 investigates the possible reasons for the anomalous cooling. The relative importance of aerosol-radiation interactions and aerosol-cloud interactions is quantified and discussed in section 5. Conclusion is given in Section 6.

\section{Model, data, and method}

\subsection{CMIP6 ESMs}

CMIP6 includes an unprecedented number of models with representations of aerosol-cloud interactions. Many also have interactive tropospheric chemistry and 
88 aerosol schemes. Six such ESMs are employed in this study: BCC-ESM1 (Wu et al., 89 2020; Zhang et al., 2021), EC-Earth-AerChem (Noije et al., 2020), GFDL-ESM4

90 (Dunne et al., 2020), MPI-ESM-1-2-HAM (Mauritsen et al., 2019), NorESM2-LM

91 (Seland et al., 2020), and UKESM1-0-LL (Sellar et al., 2019). The surface air 92 temperature simulated in corresponding models with lower-complexity are also 93 examined: BCC-CSM2-MR (Wu et al., 2019b), EC-Earth3 (Döscher et al., 2021), and 94 MPI-ESM1-2-LR (Mauritsen et al., 2019) with prescribed tropospheric chemistry and 95 aerosol; GFDL-CM4 (Held et al., 2019), NorCPM1 (Bethke et al., 2019), and 96 HadGEM3-GC31-LL (Williams et al., 2017) with prescribed tropospheric chemistry and interactive aerosol scheme. BCC-CSM2-MR, EC-Earth3, and MPI-ESM1-2-LR prescribe the anthropogenic aerosol forcings using the MACv2-SP parameterization

99 (Stevens et al., 2017). MACv2-SP approximates the observationally constrained spatial distributions of the monthly mean anthropogenic aerosol optical properties and an associated Twomey effect. Except for BCC models, the horizontal resolutions of the ESMs are the same as the corresponding lower-complexity models. A brief summary of the ESMs and the lower-complexity models is introduced in Table 1. 
Table 1. Information of the ESMs with interactive chemistry and aerosol scheme, as well as the corresponding lower-complexity models.

\begin{tabular}{|c|c|c|c|c|c|c|}
\hline Modeling group & $\begin{array}{l}\text { ESM } \\
\text { (Atmospheric } \\
\text { Resolution) }\end{array}$ & $\begin{array}{l}\text { Lower-complexity } \\
\text { models } \\
\text { (Atmospheric } \\
\text { Resolution) }\end{array}$ & $\begin{array}{l}\text { Prescribed } \\
\text { tropospheric } \\
\text { chemistry }\end{array}$ & $\begin{array}{r}\text { Prescribed } \\
\text { aerosol }\end{array}$ & $\begin{array}{l}\text { Number } \\
\text { of } \\
\text { members }\end{array}$ & References \\
\hline $\begin{array}{l}\text { Beijing Climate } \\
\text { Center (BCC) }\end{array}$ & $\begin{array}{l}\text { BCC-ESM1: the BCC } \\
\text { Earth System Model } \\
\text { version } 1 \\
\text { (T42, } 26 \text { layers } \\
\text { to } 2.914 \mathrm{hPa} \text { ) }\end{array}$ & $\begin{array}{l}\text { BCC-CSM2-MR: the } \\
\text { median resolution } \\
\text { BCC Climate System } \\
\text { Model version } 2 \\
\text { (T106, } 46 \text { layers } \\
\text { to } 1.459 \mathrm{hPa} \text { ) }\end{array}$ & $\mathrm{Y}$ & $\mathrm{Y}$ & 3 & $\begin{array}{l}\text { Wu et } \\
\text { al. }(2019 b \text {, } \\
2020) \text {; } \\
\text { Zhang et } \\
\text { al. (2021) }\end{array}$ \\
\hline $\begin{array}{l}\text { European } \\
\text { consortium of } \\
\text { meteorological } \\
\text { services, research } \\
\text { institutes, and } \\
\text { high-performance } \\
\text { computing centres }\end{array}$ & $\begin{array}{l}\text { EC-Earth-AerChem: } \\
\text { the EC-Earth } \\
\text { configuration with } \\
\text { interactive aerosols and } \\
\text { atmospheric chemistry } \\
\text { (T255, } 91 \text { layers } \\
\text { to } 0.01 \mathrm{hPa} \text { ) }\end{array}$ & $\begin{array}{l}\text { EC-Earth3: the } \\
\text { EC-Earth version } 3 \\
\text { (T255, 91 layers } \\
\text { to } 0.01 \mathrm{hPa} \text { ) }\end{array}$ & $\mathrm{Y}$ & $\mathrm{Y}$ & 1 & $\begin{array}{l}\text { Noije et al. } \\
(2020) \text {; } \\
\text { Döscher et } \\
\text { al. }(2021)\end{array}$ \\
\hline $\begin{array}{l}\text { US Department of } \\
\text { Commerce/NOAA } \\
\text { / Geophysical } \\
\text { Fluid Dynamics } \\
\text { Laboratory } \\
\text { (GFDL) }\end{array}$ & $\begin{array}{l}\text { GFDL-ESM4: the } \\
\text { GFDL Earth System } \\
\text { Model version } 4 \\
(\mathrm{C} 96,49 \text { layers } \\
\text { to } 1 \mathrm{hPa})\end{array}$ & $\begin{array}{l}\text { GFDL-CM4: the } \\
\text { GFDL Climate Model } \\
\text { version } 4 \\
(\mathrm{C} 96,33 \text { layers } \\
\text { to } 1 \mathrm{hPa})\end{array}$ & $\mathrm{Y}$ & $\mathrm{N}$ & 1 & $\begin{array}{l}\text { Dunne et } \\
\text { al. (2020); } \\
\text { Held et al. } \\
(2019)\end{array}$ \\
\hline $\begin{array}{l}\text { Max Planck } \\
\text { Institute for } \\
\text { Meteorology } \\
\text { (MPI) }\end{array}$ & $\begin{array}{l}\text { MPI-ESM-1-2-HAM: } \\
\text { the } \\
\text { HAMMOZ-Consortium } \\
\text { of MPI Earth System } \\
\text { Model } \\
\text { (T63, } 47 \text { layers } \\
\text { to } 0.01 \mathrm{hPa} \text { ) }\end{array}$ & $\begin{array}{l}\text { MPI-ESM1-2-LR: the } \\
\text { lower-resolution } \\
\text { version of MPI Earth } \\
\text { System Model } \\
\text { (T63, } 47 \text { layers } \\
\text { to } 0.01 \mathrm{hPa} \text { ) }\end{array}$ & $\mathrm{Y}$ & $\mathrm{Y}$ & 3 & $\begin{array}{l}\text { Mauritsen } \\
\text { et al. } \\
(2019) \text {; }\end{array}$ \\
\hline $\begin{array}{l}\text { Norwegian } \\
\text { Climate Center } \\
\text { (NCC) }\end{array}$ & $\begin{array}{l}\text { NorESM2-LM: the } \\
\text { lower-resolution of } \\
\text { Norwegian ESM } \\
\text { version } 2 \\
\text { (About } 2^{\circ}, 32 \text { layers } \\
\text { to } 2 \mathrm{hPa} \text { ) }\end{array}$ & $\begin{array}{l}\text { NorCPM1: the } \\
\text { Norwegian Climate } \\
\text { Prediction Model } \\
\text { version } 1 \\
\left(\text { About } 2^{\circ}, 26 \text { layers }\right. \\
\text { to } 3 \mathrm{hPa})\end{array}$ & $\mathrm{Y}$ & $\mathrm{N}$ & 3 & $\begin{array}{l}\text { Seland et } \\
\text { al. }(2020) \text {; } \\
\text { Bethke et } \\
\text { al. }(2019)\end{array}$ \\
\hline $\begin{array}{l}\text { Met Office's } \\
\text { Hadley Centre for } \\
\text { Climate Prediction } \\
\text { and Research } \\
(\mathrm{MOHC})\end{array}$ & $\begin{array}{l}\text { UKESM1-0-LL: U.K. } \\
\text { Earth System Model } \\
\text { version } 1 \\
\text { (N96, } 85 \text { layers } \\
\text { to } 85 \mathrm{~km} \text { ) }\end{array}$ & $\begin{array}{l}\text { HadGEM3-GC31-LL: } \\
\text { the Hadley Centre } \\
\text { Global Environment } \\
\text { Model in the Global } \\
\text { Coupled configuration } \\
3.1 \\
\text { (N96, } 85 \text { layers } \\
\text { to } 85 \mathrm{~km} \text { ) }\end{array}$ & $\mathrm{Y}$ & $\mathrm{N}$ & 3 & $\begin{array}{l}\text { Sellar et al. } \\
(2019) \text {; } \\
\text { Williams et } \\
\text { al. (2017) }\end{array}$ \\
\hline
\end{tabular}


Table 2 Variables used in this study.

\begin{tabular}{|c|c|c|c|}
\hline $\begin{array}{l}\text { Variable } \\
\text { name }\end{array}$ & $\begin{array}{l}\text { CMIP6 } \\
\text { diagnostic label }\end{array}$ & Description & Units \\
\hline TAS & tas & Surface air temperature & ${ }^{\circ} \mathrm{C}$ \\
\hline OSR & rsut & $\begin{array}{l}\text { All-sky outgoing shortwave radiation at } \\
\text { the top of atmosphere (TOA) }\end{array}$ & $\mathrm{W} \mathrm{m}^{-2}$ \\
\hline OSRclr & rsutcs & OSR assuming clear sky & $\mathrm{W} \mathrm{m}{ }^{-2}$ \\
\hline mmrso4 & mmrso4 & $\begin{array}{l}\text { Mass mixing ratio of sulphate aerosol in } \\
\text { the atmosphere }\end{array}$ & $\begin{array}{l}\mathrm{kg} \\
\mathrm{kg}-1\end{array}$ \\
\hline CLT & clt & Total cloud amount & $\%$ \\
\hline$r_{\text {eff }}$ & reffclwtop & cloud-top effective droplet radius & $\mu \mathrm{m}$ \\
\hline loadSO4 & & $\begin{array}{l}\text { Sulphate loading in the atmosphere, } \\
\text { calculated by mmrso } 4\end{array}$ & $\begin{array}{l}\mathrm{mg} \\
\mathrm{m}^{-2}\end{array}$ \\
\hline OSRclr_hist & & $\begin{array}{l}\text { Mean OSRclr in the historical } \\
\text { simulation from } 1850 \text { to } 1990\end{array}$ & $\mathrm{~W} \mathrm{~m}^{-2}$ \\
\hline CLT_hist & & $\begin{array}{l}\text { Mean CLT in the historical simulation } \\
\text { from } 1850 \text { to } 1990\end{array}$ & $\%$ \\
\hline
\end{tabular}

The CMIP6 historical experiment and hist-piAer experiment are employed. The historical experiment is forced by time-evolving, externally imposed natural and

112 anthropogenic forcings, such as solar variability, volcanic aerosols, greenhouse gases, 113 and aerosol emissions (Eyring et al., 2016). The hist-piAer experiment is designed by 114 the CMIP6-endorsed Aerosol Chemistry Model Intercomparison Project 115 (AerChemMIP; Collins et al., 2017). It is run in parallel with the historical experiment 116 but fixes aerosol and aerosol precursor emissions to pre-industrial conditions. 117 Therefore, the differences between these two experiments are attributable to 118 anthropogenic aerosol emissions. Note that we use the hist-piAer simulations but not 
the hist-aer simulations designed by the Detection and Attribution Model Intercomparison Project (DAMIP; Gillett et al., 2016), which resembles the historical simulations but are only forced by transient changes in aerosol. The design of the hist-piAer simulation means that it can also capture any nonlinearities resulting from GHG-driven changes in clouds.

The monthly outputs from historical and hist-piAer simulations for ESMs are used, including TAS, all-sky outgoing shortwave radiation at the top-of-atmosphere (OSR), OSR assuming clear sky (OSRclr), mass mixing ratio of sulphate aerosol in the atmosphere (mmrso4), total cloud amount (CLT), and cloud-top effective droplet radius $\left(\mathrm{r}_{\mathrm{eff}}\right)$. The corresponding lower-complexity models have conducted the historical but not the hist-piAer simulations, and only the monthly TAS output from historical simulations are used. Therefore, we focus on the ESMs, which allow a simple way of diagnosing the sources of the anomalous cooling. The main variables are summarized in Table 2.

The verification data used in this study is HadCRUT5, the monthly $5^{\circ}$ lat by $5^{\circ}$ lon gridded surface temperature (Morice et al., 2021), a blend of the Met Office Hadley Centre SST data set HadSST4 (Kennedy et al., 2019) and the land surface air temperature CRUTEM5 (Osborn et al., 2021).

\subsection{Method}

By comparing the TAS anomalies in ESMs and the lower-complexity models with HadCRUT5, our study found that TAS anomalies from 1960 to 1990 relative to 1850-1900 in ESMs and most of the lower-complexity models are on average much lower than observed, resembling a "pot-hole" shape. This period of anomalous cooling, i.e., the "pot-hole" cooling (PHC), is then quantified as the near-global mean $\left(60^{\circ} \mathrm{S}\right.$ to $\left.65^{\circ} \mathrm{N}\right)$ difference in the TAS anomaly between models and HadCRUT5 from 1960 to 1990 . The variations over the polar regions (north of $65^{\circ} \mathrm{N}$ and south of $60^{\circ} \mathrm{S}$ ) are not considered due to the lack of long-term reliable observations (Wu et al., 2019a). The PHC period coincides with a period when global emissions of $\mathrm{SO}_{2}$, the main precursor of sulphate aerosol, rapidly increased. 
The aerosol cooling due to aerosol-radiation interaction (ARI) is dominated by the contribution of sulphate aerosol as estimated by models and observations $(-0.35 \pm$ $0.5 \mathrm{~W} \mathrm{~m}^{-2}$ for the total ARI and $-0.4 \pm 0.2 \mathrm{~W} \mathrm{~m}^{-2}$ for ARI of sulphate aerosol (Myhre et al., 2013). We use the evolution of sulphate loading (loadSO4) through the historic simulation as a proxy for total aerosol concentration changes to link estimates of the impact of aerosol-forcing-sensitivity. Whilst the overall impact of aerosol forcing will also be driven by other aerosol species, we adopt this approach because the sulphates dominate estimates of aerosol-forcing-sensitivity during this period and other aerosols species can be assumed (as a $1^{\text {st }}$ order approximation) to have covaried with the $\mathrm{SO}_{2}$ emissions during this period. As such when we present estimates of the aerosol impact/loadSO4 we are presenting the impact of all aerosol species (including absorbing aerosols such as black carbon) as they covary with the sulphate concentrations during the historic period. The motivation for presenting it in this way, is we can separate differences in ESM responses to changes in aerosol amount from the differences in aerosol amount (represented by loadSO4) simulated by the ESMs.

We can estimate the impact of anthropogenic aerosol by using the difference in OSR between the historical and hist-piAer simulations, $\triangle O S R$. $\triangle O S R$ is of course involves any differences in planetary albedo, between the two simulations, including clear-sky albedo changes and any adjustments in microphysical or macroscopic properties of clouds. The aerosol-forcing-sensitivity can be calculated from a linear fit between the OSR differences and loadSO4 differences between the historical and hist-piAer simulations ( $\triangle O S R$ / $\triangle$ loadSO4). The linear fit slope measures the sensitivity of total aerosol forcing. Wilcox et al. (2015) found a large diversity of the CMIP5 models in simulating the total aerosol forcing, which arises from the diversity in global load and spatial distribution of sulphate aerosol, and differences in global mean cloud top effective radius, amongst other factors. In this study, we diagnose the OSR differences from historical simulations that also capture the temperature response. As such the OSR differences do not represent a measure of only the aerosol forcing impact but combine OSR differences arising from both the aerosol forcing and the 
temperature response to this forcing, which we will refer to in this manuscript as the aerosol-forcing-sensitivity. So, the numbers diagnosed here cannot be directly compared to aerosol forcing estimates published elsewhere, but the relative magnitude and time evolution of the aerosol-forcing-sensitivity is informative of the aerosol radiative role in the simulations we explore here.

The aerosol-forcing-sensitivity can be further partitioned into a contribution from aerosol-radiation interactions (ARI), and aerosol-cloud interactions (ACI). ARI quantifies the influence of aerosols on clear-sky radiative fluxes. ACI is due to the impact of aerosol-induced changes in the properties of clouds, such as cloud spatial extent (amount), cloud longevity (lifetime), and cloud albedo on radiative fluxes. ARI and ACI can be readily estimated from the CMIP6 output because annual mean cloud amount, CLT, and the top-of-atmosphere radiative flux assuming only clear-sky, OSRclr, are available for all the CMIP6 ESMs. For each model, the OSR from clouds (OSRcld) can therefore be estimate as OSR-((1-CLT/100.)*OSRclr). As shown in the Appendix, the aerosol-forcing-sensitivity can be expressed as:

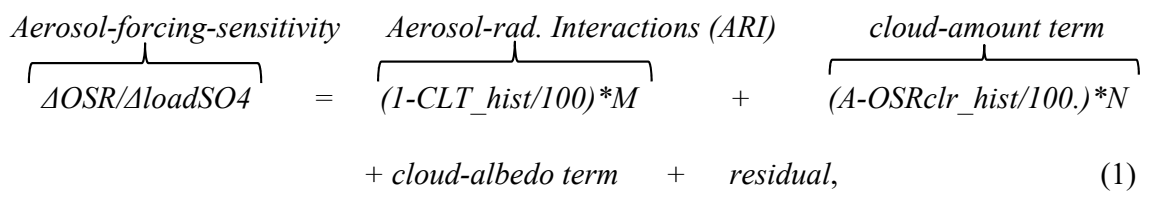

where CLT_hist and OSRclr_hist are the mean cloud amount (CLT) and clear-sky OSR (OSRclr) in the historical simulation, and $\mathrm{M}, \mathrm{N}$ and $\mathrm{A}$ are empirically determined parameters. The parameter $\mathrm{M}$ is the slope of a linear fit of $\Delta \mathrm{OSR}$ clr to $\Delta$ loadSO4, and therefore measures the strength of the aerosol-radiation interactions in each model. The term (1-CLT_hist/100.)*M can therefore be identified with ARI.

The parameter $\mathrm{A}$ is the slope of a linear fit of $\triangle \mathrm{OSR}$ cld to $\triangle \mathrm{CLT}$, and therefore measures the correlation of the short wave radiation reflected by clouds with changes in cloud amount. The parameter $\mathrm{N}$ is the slope of a linear fit of $\triangle \mathrm{CLT}$ to $\triangle$ loadSO4, and therefore measures the sensitivity of cloud amount to aerosols. Note that changes in cloud amount by definition also affect the fraction of clear-sky, hence increases in 
OSRcld due to increases in CLT (i.e., $A^{*} N$ ) can be partly offset by changes in area of clear-sky containing aerosols (OSRclr_hist*N). The second term on the right-hand side of Eq. (1) therefore contributes to the ACI, specifically it is the part of ACI that is linearly proportional to changes to cloud fraction. It is roughly analogous to the "cloud lifetime effect" (Albrecht, 1989), but is sensitive to any aerosol-induced cloud fraction changes (Lohmann and Feichter, 2005), including any slow adjustments in clouds due to feedbacks within the Earth System.

In addition to depending on $\triangle \mathrm{CLT}, \mathrm{ACI}$ is also influenced by any changes in cloud-albedo that might occur independently of cloud-amount changes. Such adjustments would include increases in simulated cloud-droplet effective radius without accompanying changes in cloud cover. Changes purely in the brightness of clouds, without changes in macroscopic properties of clouds, are difficult to identify from the CMIP6 output because all the bulk-properties of clouds co-vary over the course of the projections. However, subtracting ARI and the cloud-amount term from the aerosol-forcing-sensitivity gives a residual that is, by definition, linearly independent of cloud fraction differences (since by construction these have been regressed out). This residual can then be interpreted as due to differences in the albedo of clouds between the historical and hist-piAer, and will be called the "cloud-albedo term". Note that this method of calculation implies that purely albedo effects cannot be distinguished from general residual terms that result from the linear approximation made.

Note that our decomposed ACI does not correspond exactly to the definitions of "first" and "second" aerosol indirect effects. For example, the first indirect effect is properly defined as variations of aerosol forcing when cloud droplet number concentration varies at a constant value of the cloud liquid water path. This effect cannot be isolated from the available CMIP6 output.

\section{The "pot-hole" bias in CMIP6 ESMs}



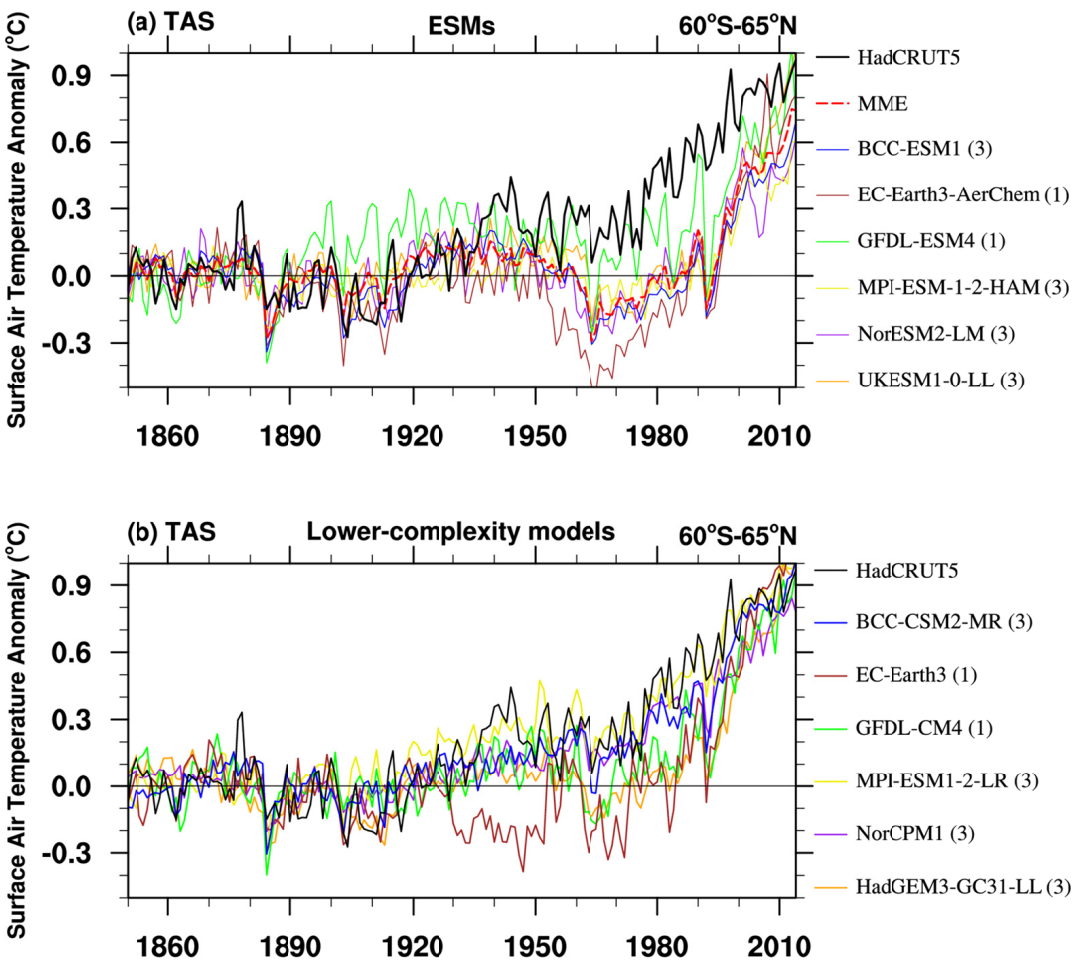

Figure 1. (a) Historical near-global mean $\left(60^{\circ} \mathrm{S}\right.$ to $\left.65^{\circ} \mathrm{N}\right)$ surface air temperature (TAS) anomalies from HadCRUT5 (thick black line), the multi-member ensemble mean for each ESM (MMM, solid color lines), and their ensemble (MME, dashed red line). (b) is the same as (a), but for the lower-complexity models. The baseline is from 1850 to 1900 . Units: ${ }^{\circ} \mathrm{C}$. Value in bracket is the number of available members for each model.

Figure 1a shows the near-global averaged time series of annual mean TAS anomaly relative to 1850 to 1900 in HadCRUT5, the multi-member ensemble means (MMMs) for BCC-ESM1, MPI-ESM-1-2-HAM, NorESM2-LM and UKESM1-0-LL, and the first member for EC-Earth3-AerChem and GFDL-ESM4 during the historical period from 1850 to 2014. Only the first member for EC-Earth3-AerChem and GFDL-ESM4 is examined here, because only their first member is available for the hist-piAer experiement. The unforced, long-term drifts in TAS may occur in some of the ESMs, as estimated by their control simulation under pre-industrial conditions 
250 (Yool et al., 2020). We have not accounted for long-term control simulation drifts in

251 our study as we are assuming that our focus on inter-decadal scale variability of TAS anomalies is likely to be fairly insensitive to any century scale drifts.

The TAS anomaly in HadCRUT5 is generally above the baseline climate from the 1940 s onwards, and warms fastest from the 1980s to 1990s. Compared with the observations, all the ESM simulations have negative TAS anomaly biases after the 1940 s, which are also evident in the ensemble-mean historical TAS of 25 CMIP6 models with and without interactive chemistry schemes (Flynn and Mauritsen, 2020). In the ESMs and their ensemble mean (MME), the cold anomaly biases resemble a "pot-hole" shape (Fig.1a), which is relatively small before the 1950s and after the 2000s but expands from the 1960s to 1990s. To reduce the impact of cooling responses to the Pinatubo eruption in the early 1990s and the change in the spatial pattern of the emissions, we mainly focus on the excessively cold anomaly from 1960 to 1990 in this study. The period of anomalous cold in the global mean from 1960 to 1990 in model simulations is defined as the "pot-hole" cooling (PHC) as described in section 2.3. Table 3 shows the TAS anomaly biases in two typical periods, three decades before the PHC period (1929 1959) and the PHC period (1960 1990). The biases are all negative in the previous era; the negative biases increase in the PHC period and become larger than $-0.3^{\circ} \mathrm{C}$ in all the ESMs except for GFDL-ESM4. The PHC ranges from $-0.20^{\circ} \mathrm{C}$ to $-0.58^{\circ} \mathrm{C}$ among the MMMs with a standard deviation of $0.11^{\circ} \mathrm{C}$, but intra-model spread of PHC for the three available members in BCC-ESM1, MPI-ESM-1-2-HAM, NorESM2-LM, and UKESM1-0-LL is relatively smaller. That is, model structural uncertainty is more responsible for PHC than internal climate variability.

Table 3. Biases in near-global averaged TAS anomalies relative to 1850-1900 from the multi-member ensemble mean (MMM) and standard deviation across members

(SD) for each ESM and the corresponding lower-complexity model during 1929 1959, and the "pot-hole" period (1960 1990). The ensemble mean of MMMs 
279 (MME) and the SD across MMMs are also examined. The anomalous cooling larger 280 than $-0.3^{\circ} \mathrm{C}$ is bolded. Biases are relative to the HadCRUT5.

\begin{tabular}{|c|c|c|c|c|c|}
\hline \multirow{2}{*}{ ESMs } & $1929 \sim 1959$ & $\begin{array}{l}1960 \sim 1990 \\
\text { (PHC) }\end{array}$ & \multirow{2}{*}{$\begin{array}{l}\text { Lower-complexity } \\
\text { models }\end{array}$} & 1929 1959 & $\begin{array}{l}1960 \sim 1990 \\
\text { (PHC) }\end{array}$ \\
\hline & $\begin{array}{c}\text { MMM } \\
(\mathrm{SD})\end{array}$ & $\begin{array}{l}\text { MMM } \\
\text { (SD) }\end{array}$ & & $\begin{array}{l}\text { MMM } \\
(\mathrm{SD})\end{array}$ & $\begin{array}{l}\text { MMM } \\
\text { (SD) }\end{array}$ \\
\hline BCC-ESM1 & $\begin{array}{l}-0.12 \\
(0.01)\end{array}$ & $\begin{array}{l}\mathbf{- 0 . 4 5} \\
(0.07)\end{array}$ & BCC-CSM2-MR & $\begin{array}{l}-0.09 \\
(0.01)\end{array}$ & $\begin{array}{l}-0.10 \\
(0.01)\end{array}$ \\
\hline EC-Earth-AerChem & -0.27 & -0.58 & EC-Earth3 & -0.37 & -0.37 \\
\hline GFDL-ESM4 & -0.02 & -0.20 & GFDL-CM4 & -0.12 & -0.26 \\
\hline MPI-ESM-1-2-HAM & $\begin{array}{l}-0.16 \\
(0.01)\end{array}$ & $\begin{array}{l}\mathbf{- 0 . 3 9} \\
(0.03)\end{array}$ & MPI-ESM1-2-LR & $\begin{array}{l}0.03 \\
(0.03)\end{array}$ & $\begin{array}{l}0.01 \\
(0.01)\end{array}$ \\
\hline NorESM2-LM & $\begin{array}{l}-0.16 \\
(0.04)\end{array}$ & $\begin{array}{l}\mathbf{- 0 . 4 1} \\
(0.04)\end{array}$ & NorCPM1 & $\begin{array}{l}-0.10 \\
(0.03)\end{array}$ & $\begin{array}{l}-0.08 \\
(0.04)\end{array}$ \\
\hline UKESM1-0-LL & $\begin{array}{l}-0.10 \\
(0.09)\end{array}$ & $\begin{array}{l}\mathbf{- 0 . 3 8} \\
(0.08)\end{array}$ & HadGEM3-GC31-LL & $\begin{array}{l}-0.16 \\
(0.02)\end{array}$ & $\begin{array}{l}-\mathbf{- 0 . 3 3} \\
(\mathbf{0 . 0 3})\end{array}$ \\
\hline MME & $\begin{array}{l}-0.14 \\
(0.08)\end{array}$ & $\begin{array}{l}\mathbf{- 0 . 4 0} \\
(0.11)\end{array}$ & & & \\
\hline
\end{tabular}

281

The PHC bias is generally smaller in the corresponding lower-complexity models

285 anomalous TAS biases are about $-0.10^{\circ} \mathrm{C}$ in $\mathrm{BCC}-\mathrm{CSM} 2-\mathrm{MR}$ and $0.01^{\circ} \mathrm{C}$ in 286 MPI-ESM1-2-LR, which are also close to the biases in previous era $\left(-0.09^{\circ} \mathrm{C}\right.$ in 287 BCC-CSM2-MR and $0.03^{\circ} \mathrm{C}$ in MPI-ESM1-2-LR in 1929 1959). EC-Earth3 also 288 prescribes chemistry and aerosol but has a large PHC bias $\left(-0.37^{\circ} \mathrm{C}\right)$. The anomalous 289 cooling bias is also evident in previous era (1929 1959) with comparable amplitude.

290 However, the anomalous TAS biases in the second and third historical members of

291 EC-Earth3 during the PHC period are smaller and both positive $\left(0.07^{\circ} \mathrm{C}\right.$ and $\left.0.24^{\circ} \mathrm{C}\right)$

292 in our further examination. That is, TAS in EC-Earth3 may be sensitive to initial 293 condition and has been noted in Döscher et al. (2021). The PHC biases in GFDL-CM4 
and HadGEM3-GC31-LL with prescribed chemistry and interactive aerosol scheme, are comparable with that in the corresponding ESMs, but the biases grow slower from previous era: $-0.14{ }^{\circ} \mathrm{C}$ in GFDL-CM4 v.s. $-0.18{ }^{\circ} \mathrm{C}$ in GFDL-ESM4, $-0.17{ }^{\circ} \mathrm{C}$ in HadGEM3-GC31-LL v.s. $-0.28^{\circ} \mathrm{C}$ in UKESM1-0-LL. The NorCPM1 also employs an interactive aerosol scheme but has a small anomalous TAS bias $\left(-0.08^{\circ} \mathrm{C}\right)$, which is due to the overestimated tropical and southern hemispheric warming (Fig.2k). Generally, the different behaviours seen in Fig.1 suggest that aerosol forcings may be overestimated in the ESMs and the anomalous cooling in ESMs is a result of the extra complexity associated with interactive chemistry and aerosol processes.

The evolution of zonal mean annually averaged TAS anomalies in HadCRUT5, and the MMM for each ESM and lower-complexity model are further examined in Fig.2. In HadCRUT5, TAS anomalies are generally positive after the 1940s. The most significant TAS anomalies are evident in the late $20^{\text {th }}$ Century and at the beginning of the $21^{\text {st }}$ Century, especially over the NH midlatitudes, where the TAS anomalies are larger than $1.0^{\circ} \mathrm{C}$. The results from BCC-CSM2-MR and MPI-ESM1-2-LR agree well with the observations. However, the ESMs and the other lower-complexity models simulate pronounced cold anomalies over NH subtropical-to-high latitudes during the PHC period. Figure 2 also shows the evolution of surface anthropogenic $\mathrm{SO}_{2}$ emissions (the contours). They rapidly increase during the PHC period. The latitudes of the cooling centers are spatially co-located with the $\mathrm{SO}_{2}$ emission sources - North America and East Asia (at around $30^{\circ} \mathrm{N}$ ) and Western Europe (at around $50^{\circ} \mathrm{N}$ ). The 315 emission centers generally move south around the 1990s. European and North 316 American $\mathrm{SO}_{2}$ emissions have reduced the since the 1980s; East Asian emissions 317 clearly increased from 2000 to 2005, followed by a decrease with large uncertainties 318 (Aas et al., 2020). 

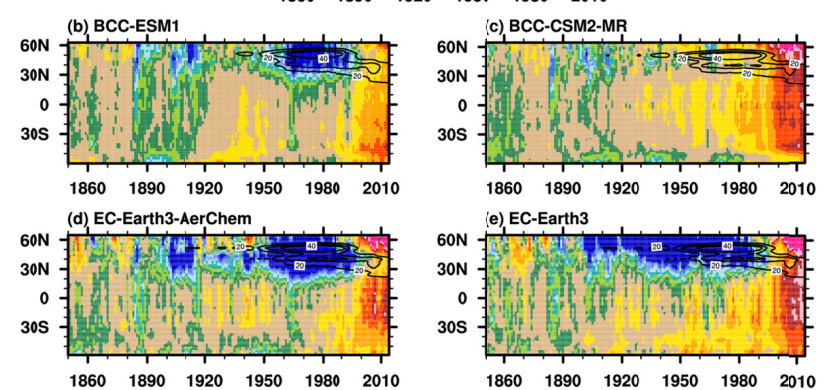

$\begin{array}{llll}1920 & 1950 & 1980 & 2010\end{array}$ (e) EC-Earth3
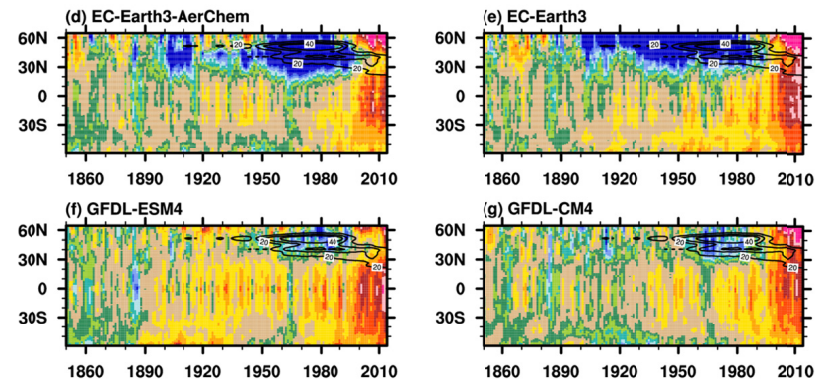

$\begin{array}{llllll}1860 & 1890 & 1920 & 1950 & 1980 & 2010\end{array}$
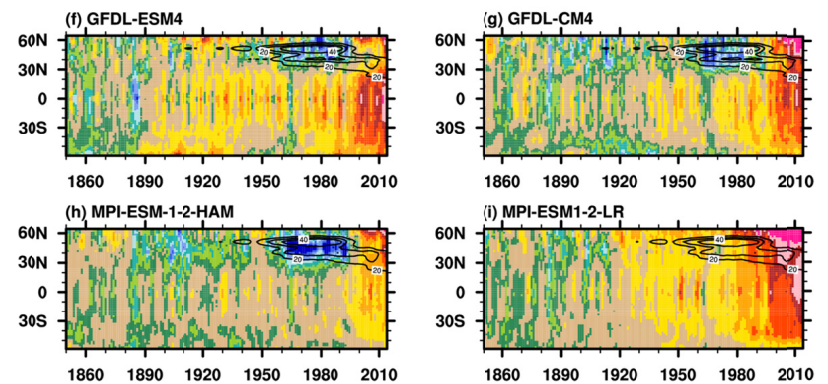

$\begin{array}{llllll}1860 & 1890 & 1920 & 1950 & 1980 & 2010\end{array}$
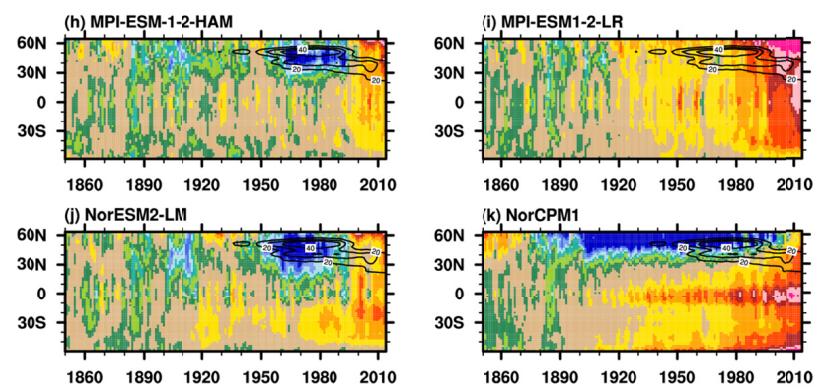

(k) NorCPM1
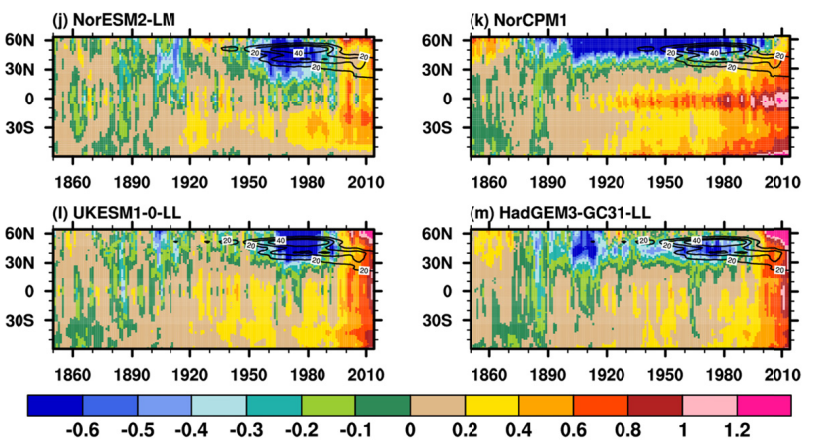

Figure 2. Time-latitude cross-section for annual-mean TAS anomalies (shaded) from (a) HadCRUT5, the MMM in each ESM (left panel), and the corresponding lower-complexity model (right panel). The anomalies are related to the $1850 \sim 1900$ mean. Units: ${ }^{\circ} \mathrm{C}$. Contours range from 20 to $40 \mathrm{ng} \mathrm{m}^{-2} \mathrm{~s}^{-1}$ with an interval of $10 \mathrm{ng} \mathrm{m}^{-2} \mathrm{~s}^{-1}$ show the zonal mean anthropogenic surface $\mathrm{SO}_{2}$ emission provided by 

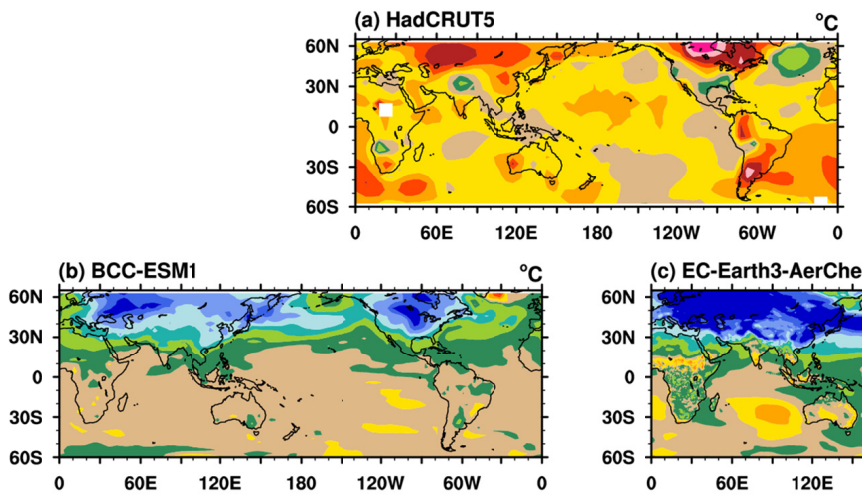

(c) EC-Earth3-AerChem
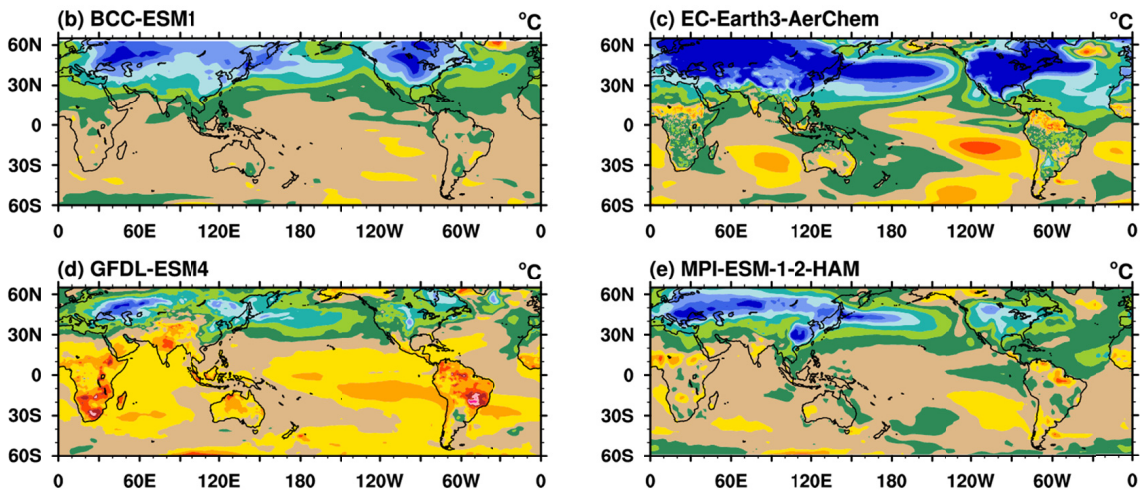

(e) MPI-ESM-1-2-HAM

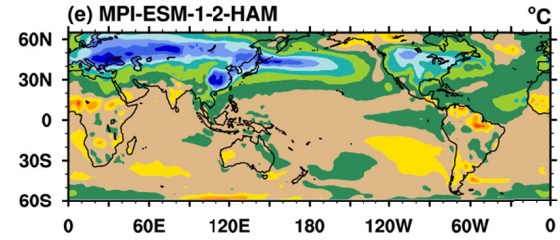

(f) NorESM2-LM

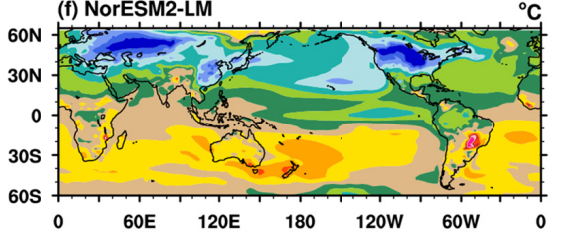

(g) UKESM1-0-LL
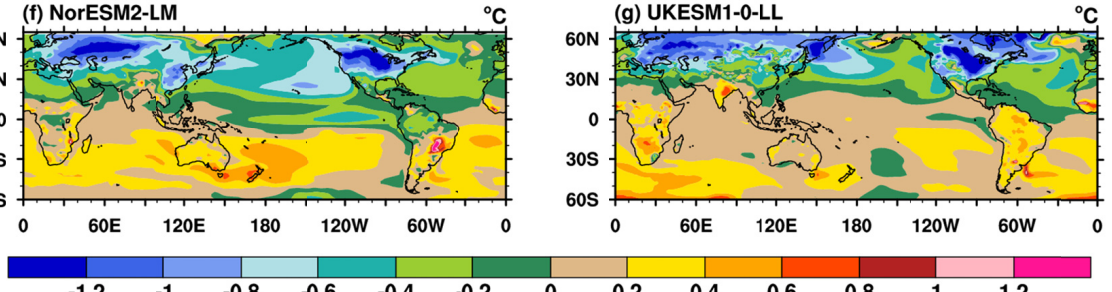

Figure 3. The TAS anomalies during the "pot-hole" period $(1960$ 1990) from (a) HadCRUT5 and

(b-g) the MMMs in each of the ESMs. The anomalies are relative to the $1850 \sim 1900$ mean. Units: ${ }^{\circ} \mathrm{C}$.

Figure 3 examines the spatial structure of TAS anomalies in HadCRUT5 and ESMs in the PHC period. The TAS anomalies in HadCRUT5 are generally positive and are the largest over Eurasia and North America. The warm anomalies are on average more than $0.4{ }^{\circ} \mathrm{C}$ along the $30^{\circ} \mathrm{N} \sim 60^{\circ} \mathrm{N}$ latitudinal belt. However, the ESMs show anomalies with the opposite sign. The $\mathrm{PHC}$ is pronounced over major $\mathrm{SO}_{2}$ emission centers (Western Europe, East Asia, and the east US) and their downstream regions.

345 The cold anomalies over Eurasia and North America are lower than $-0.6^{\circ} \mathrm{C}$ in the

ESMs. 

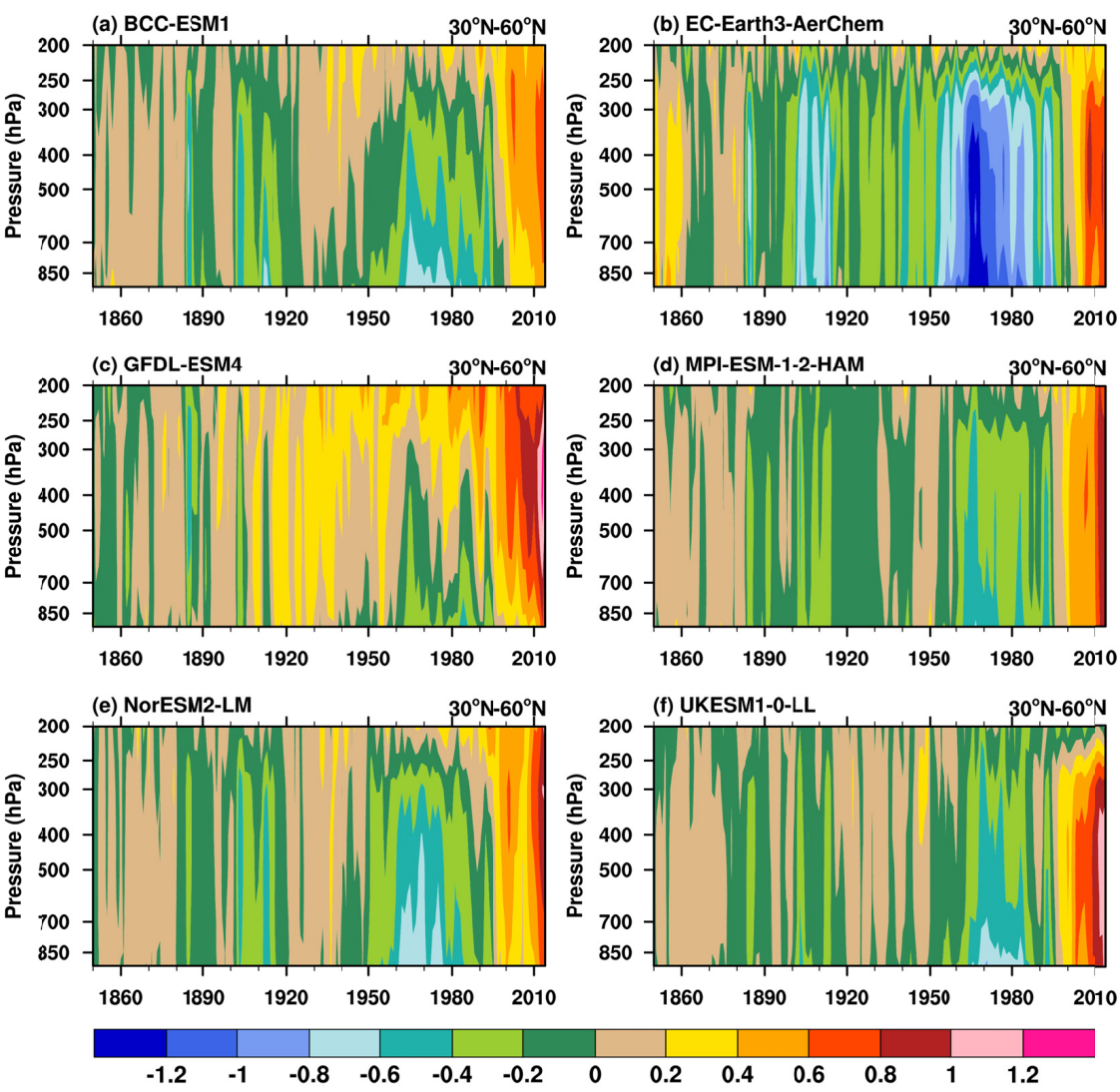

Figure 4 Time-height cross-section of temperature anomalies averaged over the $30^{\circ} \mathrm{N} \sim 60^{\circ} \mathrm{N}$ for the

MMM of each ESM. The anomalies are relative to the $1850 \sim 1900$ mean. Units: ${ }^{\circ} \mathrm{C}$.

The vertical structures of temperature anomalies over the $30^{\circ} \mathrm{N} \sim 60^{\circ} \mathrm{N}$ are also examined (Fig.4). The cold anomalies during the PHC period are the strongest at lower levels and extend into the upper troposphere. This is distinct from the amplified upper-tropospheric warming in the tropics in response to greenhouse gases (Thorne et al., 2011). The cooling extends to higher altitudes in the troposphere when an explosive volcanic eruption occurs, such as the 1963 Agung eruption, the 1974 Fuego eruption, the 1982 El Chichon eruption, and the 1991 Mount Pinatubo eruption. 

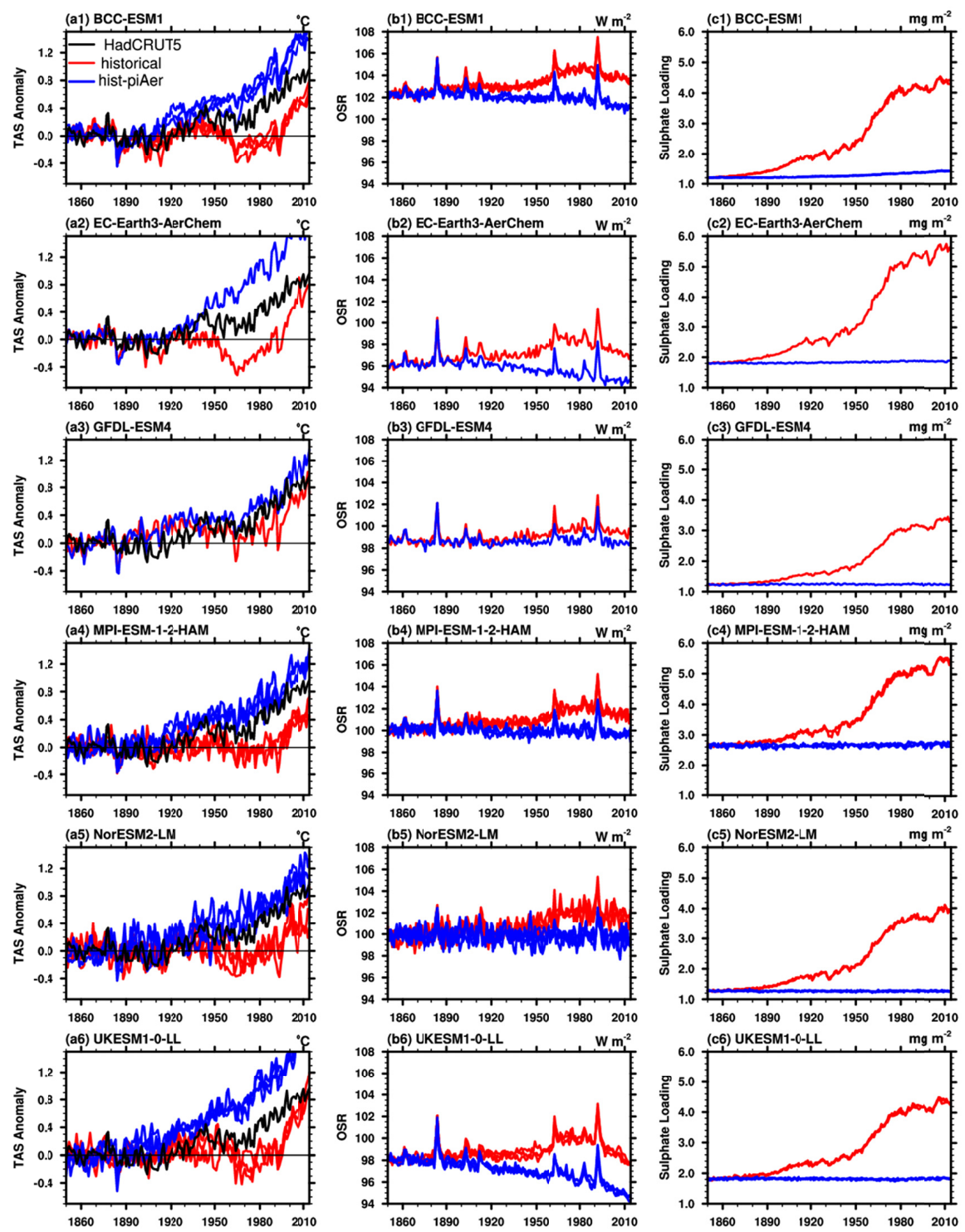

Figure 5. Evolutions of global annual means of (a1-a6) TAS anomalies (left panel, units: $\left.{ }^{\circ} \mathrm{C}.\right)$, (b1-b6)

outgoing shortwave radiation at TOA (OSR, middle panel, units: $\mathrm{W} \mathrm{m}^{-2}$ ), and (c1-c6) sulphate loading

(right panel, units: $\mathrm{mg} \mathrm{m}^{-2}$ ) in HadCRUT5 (black line), each ESM member of the historical (red lines), 
The differences between the historical and hist-piAer simulations help to investigate the impact of anthropogenic aerosol emissions and its possible contribution to the PHC biases. In this section, we examine the TAS, OSR, and sulphate loading differences, and look in detail at their relationship. As shown by the evolution of TAS anomalies in the two experiments (Fig.5, left panel), during the PHC period TAS anomalies in HadCRUT5 (black line) are higher than those in the historical members but lower than those in the hist-piAer members in all ESMs. That is, the model responses to anthropogenic aerosol emission are larger than the amplitude of the PHC. The temporal evolution of the OSR corresponds with that of the TAS but occurs in the opposite direction (middle panel). The OSR differences between the historical and hist-piAer simulations are larger in the ESMs that show big TAS differences (e.g. EC-Earth3-AerChem and UKESM1-0-LL). The temporal evolution of the sulphate loading (right panel) corresponds with the changes in anthropogenic surface $\mathrm{SO}_{2}$ emissions (contours in Fig.2). Accordingly, the sulphate loading differences are relatively small in the $19^{\text {th }}$ Century, mildly increase in the first half of the $20^{\text {th }}$ Century, grow most rapidly during the PHC period, and remain high afterward. In comparison with the TAS and OSR differences, the intra-model spread of sulphate loading for each ESM is relatively small. However, the inter-model diversity of sulphate loading is large. For example, the sulphate loading difference between the historical and hist-piAer experiments around the year 2000 is about $4 \mathrm{mg} \mathrm{m}^{-2}$ in EC-Earth3-AerChem, almost twice of that in GFDL-ESM4. With similar anthropogenic $\mathrm{SO}_{2}$ emission rates, the lower sulphate loading difference in GFDL-ESM4 indicates it has a shorter sulphate aerosol residence time than that in EC-Earth3-AerChem, which may be due to their different sulphate production and deposition schemes. The large inter-model diversity is also evident in CMIP5 models (Wilcox et al., 2015).

The latitudinal movement of the $\mathrm{SO}_{2}$ emission center from the 1990s affects the relative strength of aerosol forcing. Due to the more rapid oxidation at lower latitudes, 
390 an equatorward shift in $\mathrm{SO}_{2}$ emissions around 1990s result in a more efficient 391 production of sulphate and stronger aerosol forcing (Manktelow et al., 2007). The 392 northern mid-latitude temperature is also more sensitive to the distribution of aerosols, 393 which is approximately twice as large as the global average (Collins et al., 2013; 394 Shindell and Faluvegi, 2009). Therefore, we focus on the relationships between TAS, 395 OSR and sulphate loading after 1900 when $\mathrm{SO}_{2}$ emissions changes are dominated by 396 its anthropogenic component, and before 1990 to reduce the effects of spatial changes 397 in anthropogenic $\mathrm{SO}_{2}$ emission centers and the uncertainty of model response to the 3981991 Mount Pinatubo eruption. As shown in Fig.6a, the TAS differences between the 399 historical and hist-piAer simulations vary linearly with the differences in the sulphate 400 loading for each ESM. The OSR differences are also linearly correlated with sulphate 401 loading differences for all models except UKESM1-0-LL (Fig.6b). It is interesting that 402 this nonlinearity is also observed in HadGEM2, a predecessor of UKESM1 (Wilcox et 403 al., 2015). 
https://doi.org/10.5194/acp-2021-570

Preprint. Discussion started: 15 July 2021

(c) Author(s) 2021. CC BY 4.0 License.
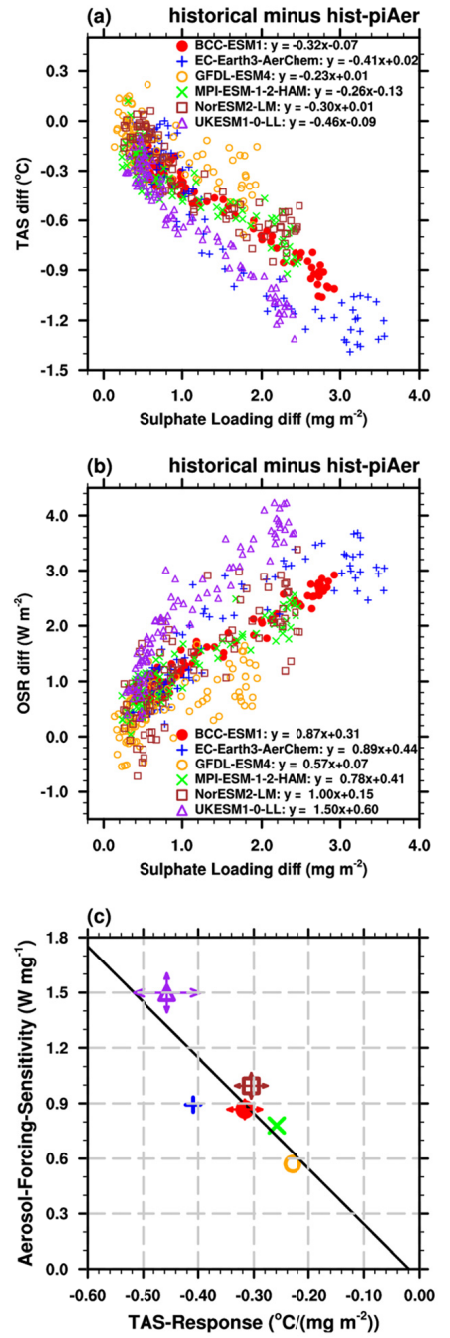

Figure 6. Scatters of 1900-1990 yearly sulphate loading differences between the historical and hist-piAer simulations (x-axis) versus (a) TAS differences and (b) OSR (y-axis). Results are from MMM in each ESM. The captions are the linear fitting equations. (c) shows the TAS response (x-axis) and aerosol-forcing-sensitivity (y-axis) which is equal to slope of linear fitting for each ESM (markers), and the corresponding intra-model spread (arrows).

The slope of the linear fitting equation between TAS (OSR) and sulphate loading as shown in the captions in Fig.6a (Fig.6b) is a measure of the sensitivity of TAS (aerosol forcing) to perturbations in atmospheric aerosol. Moreover, TAS-response 
423 and aerosol-forcing-sensitivity are linearly correlated across the ESMs (Fig.6c). That

424 is, the strength of the TAS-response can be understood as the magnitude of 425 aerosol-forcing-sensitivity within each ESM. The similarities between the strength of 426 TAS-response and aerosol-forcing-sensitivity indicate the dominant role of the aerosol 427 cooling effect. The TAS-response and aerosol-forcing-sensitivity in UKESM1-0-LL 428 (the purple marker in Fig.6c) are the strongest, as well as their intra-model spread (the 429 length of arrows), indicating that TAS and aerosol forcing in this model are relatively 430 more susceptible to changes in aerosol. The TAS-response and 431 aerosol-forcing-sensitivity is the lowest in GFDL-ESM4.
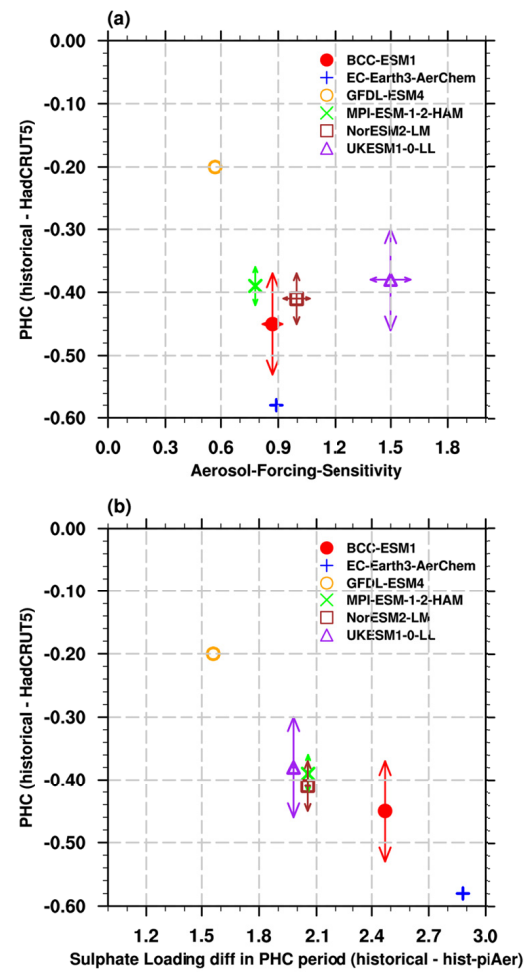

427 Figure 7. Pot-hole Cooling (PHC) bias in ESMs $\left({ }^{\circ} \mathrm{C}\right.$ ) versus (a) the aerosol-forcing-sensitivity (W $\mathrm{mg}^{-1}$ ) and (b) sulphate loading differences $\left(\mathrm{mg} \mathrm{m}^{-2}\right)$ during the PHC period. The arrows show the uncertainty ranges among the members in each ESM. 
The aerosol-forcing-sensitivity may be partly responsible for the PHC bias. Figure 7a shows the PHC biases versus the aerosol-forcing-sensitivity (markers) and their intra-model spread (arrows). The uncertainty of aerosol-forcing-sensitivity (length of the horizontal arrows) in each ESM is smaller than the PHC bias uncertainty (length of the vertical arrows). Despite the intra-model spread, the PHC and aerosol-forcing-sensitivity seem to be negatively correlated. GFDL-ESM4 has the weakest aerosol-forcing-sensitivity $\left(\sim 0.60 \mathrm{~W} \mathrm{mg}^{-1}\right)$ and the smallest PHC $\left(-0.20^{\circ} \mathrm{C}\right)$. The amplitude of PHC in BCC-ESM1, MPI-ESM-1-2-HAM, and NorESM2-LM are generally comparable, as is their aerosol-forcing-sensitivity. However, in EC-Earth3-AerChem, the aerosol-forcing-sensitivity is close to those in BCC-ESM1, MPI-ESM-1-2-HAM, and NorESM2-LM, but the PHC is more than $0.1^{\circ} \mathrm{C}$ lower than the others. In UKESM1-0-LL, the aerosol-forcing-sensitivity is the strongest $(\sim 1.5 \mathrm{~W}$ $\mathrm{mg}^{-1}$ ) but not the PHC bias. Therefore, the aerosol-forcing-sensitivity may be an important contributor to PHC bias but cannot fully explain the inter-model diversity in the PHC bias.

As shown by the $\mathrm{X}$-axis in Fig. $7 \mathrm{~b}$, the sulphate loading differences between the historical and hist-piAer experiments during the PHC period are large among ESMs, which are about $1.5 \mathrm{mg} \mathrm{m}^{-2}$ in GFDL-ESM4 but approximately $2.9 \mathrm{mg} \mathrm{m}^{-2}$ in EC-Earth3-AerChem. Examination of the sulphate loading differences during the PHC period and PHC biases shows that the PHC bias is generally larger in models with higher sulphate loading over this period (Fig.7b). Therefore, the PHC biases may be also attributable to sulphate loading related structural differences between ESMs.

\section{Discussion}

\subsection{The proportions of ARI and ACI}

There are significant differences in the aerosol-forcing-sensitivity among ESMs (Fig.6b). The aerosol-forcing-sensitivity in UKESM1-0-L is almost three times of that in GFDL-ESM4. Due to the uncertainties in physical processes and cloud parameterizations, the dominant component (ARI or ACI) of 

for all aerosol components in the quantification of the total effect because of its dominant contribution to anthropogenic aerosol load during this period and its covariation with the other aerosol species.

464
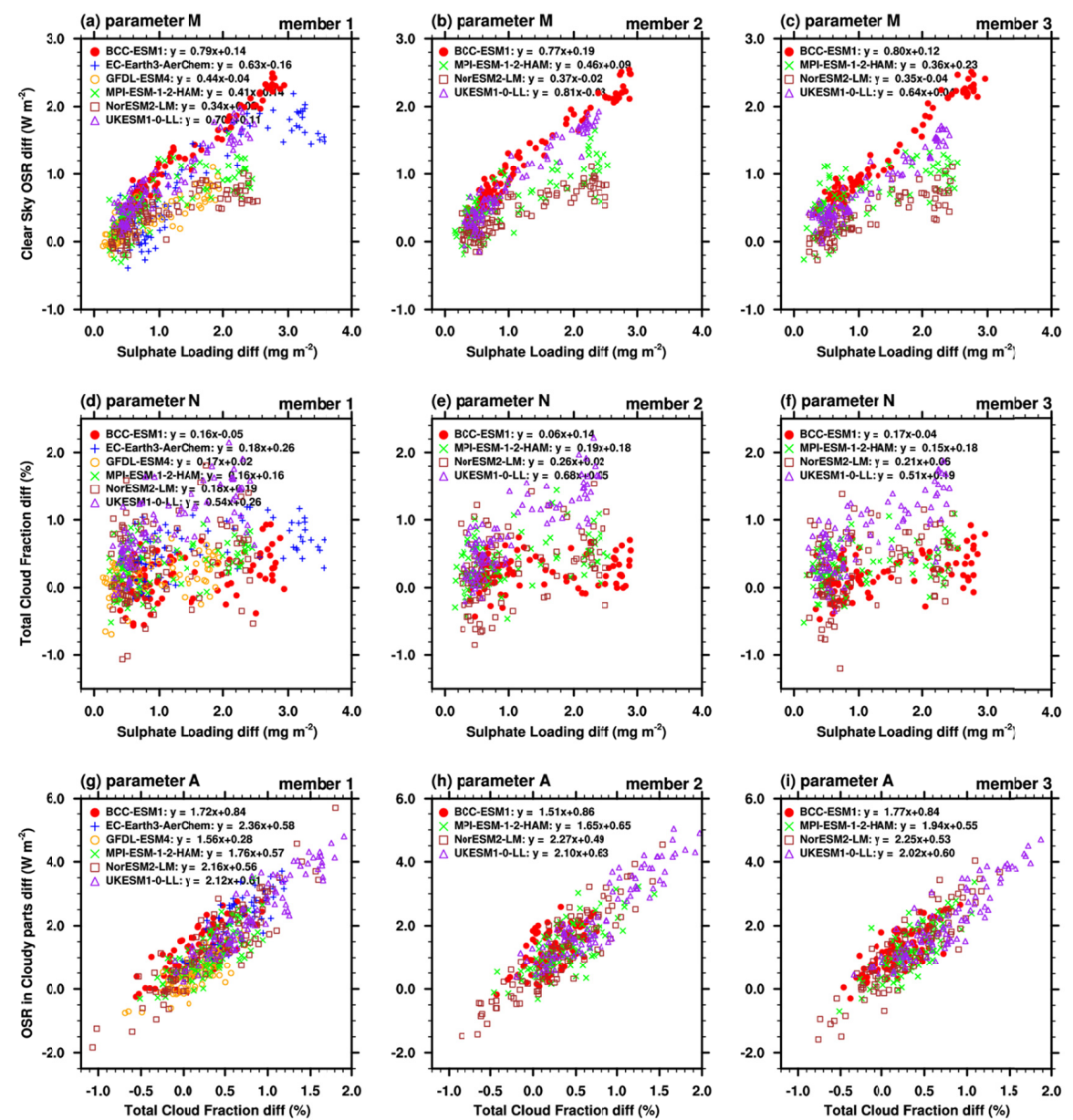

Figure 8. Annual mean differences between the historical and hist-piAer simulations in the ESM

members during 1900 to 1990 period for (a-c) sulphate loading $\left(\mathrm{mg} \mathrm{m}^{-2}\right)$ versus clear-sky OSR (OSRclr,

$\mathrm{W} \mathrm{m}^{-2}$ ), (d-f) sulphate loading versus total cloud fraction (\%), and (g-i) total cloud fraction versus OSR 
470 in cloudy parts $\left(\mathrm{W} \mathrm{m}^{-2}\right)$. Slopes of the linear fitting equations from the top row to the bottom row refer

471 to the parameters $\mathrm{M}, \mathrm{N}$, and $\mathrm{A}$, respectively.

471

The ARI can be generally parameterized as (1-CLT_hist/100.)*M, where

480 CLT_hist is cloud amount in the historical simulation and parameter $M$ is a measure of 481 the strength of aerosol-radiation interactions (AOSRclr/AloadSO4). Parameter $\mathrm{M}$ 482 varies widely from about $0.35 \mathrm{~W} \mathrm{mg}{ }^{-1}$ in NorESM2-LM to about $0.79 \mathrm{~W} \mathrm{mg}^{-1}$ in 483 BCC-ESM1 (captions in Fig.8a-8c). Since parameter M does not change much among 484 ensemble members in each ESM, their ARI is similar. That is, the impact of internal 485 climate variability on the ARI is relatively small, which is consistent with the 486 quantitative analysis in Fig.9 (Red bars).

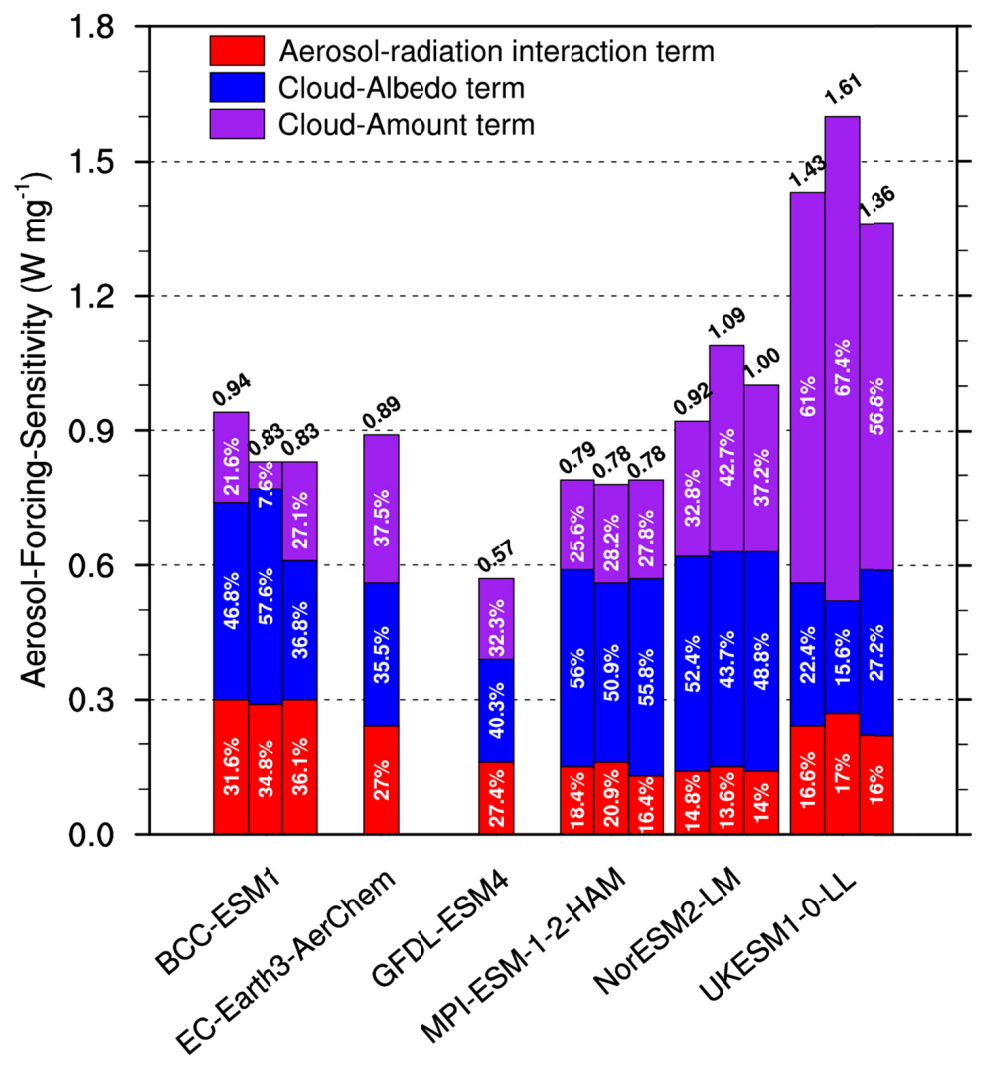


Figure 9. Total aerosol-forcing-sensitivity from each member in ESMs. The number marked on the top is the total aerosol-forcing-sensitivity. Partition of aerosol-radiation interaction term, cloud-albedo term, and cloud-amount term are marked in the corresponding color bars. Unit: $\mathrm{W} \mathrm{mg}^{-1}$.

484

The ACI can be estimated from the difference between the aerosol-forcing-sensitivity and the ARI. The proportion of the aerosol-forcing-sensitivity arising from the ACI is higher than $64 \%$ in all ESMs (Fig.9). The inter-model variation of the ACI $\left(0.37 \mathrm{~W} \mathrm{mg}^{-1}\right)$ is much larger than that for the ARI $\left(0.09 \mathrm{~W} \mathrm{mg}^{-1}\right)$. For example, the ACI in UKESM1-0-LL $\left(\sim 1.2 \mathrm{~W} \mathrm{mg}^{-1}\right)$ is higher than all the others and is about three times of that in GFDL-ESM4 (0.41 W $\mathrm{mg}^{-1}$ ). This demonstrates that differences in the aerosol-forcing-sensitivity across the ESMs are dominated by the differences in their individual representation of ACI. The intra-model variations in the ACI are also larger than that for the ARI. That is because the intra-model variations of the ACI are influenced by the effects of climate system internal variability on aerosol-induced cloud microphysics, with cloud radiative properties and cloud lifetimes varying regionally. The intra-model variations are attributable to the differences in atmospheric circulation among different ensemble members, which may affect the geographical distributions of aerosols and clouds and lead to a different magnitude of interactions.

The quantitative analysis in Fig.9 also indicates that ESMs with similar aerosol-forcing-sensitivity may have different contributions from ARI and ACI. The aerosol-forcing-sensitivity is similar in BCC-ESM1, EC-Earth3-AerChem, MPI-ESM-1-2-HAM and NorESM2-LM, but the fractional contribution from the ACI is the largest in NorESM2-LM and its ARI is less than half of that in BCC-ESM1. Generally, BCC-ESM1 has the largest fractional ARI contribution (34\%), whereas NorESM2-LM has the largest fraction of ACI contribution (86\%).

\subsection{The proportions of cloud-amount and cloud-albedo terms}



properties. This includes the cloud-albedo effects (or 'Twomey' effect), referred to as the radiative forcing part of ACI, and effects of aerosols on the macroscopic properties of clouds (for example, cloud extent and lifetime), referred to as the adjustments part of ACI. However, it is complicated to separate these two parts of ACI directly using available CMIP6 diagnostics, because the former is most accurately defined as a change in cloud albedo with all other cloud properties held constant (i.e., a change in cloud-droplet number concentration only), whilst the latter allows cloud properties to respond.
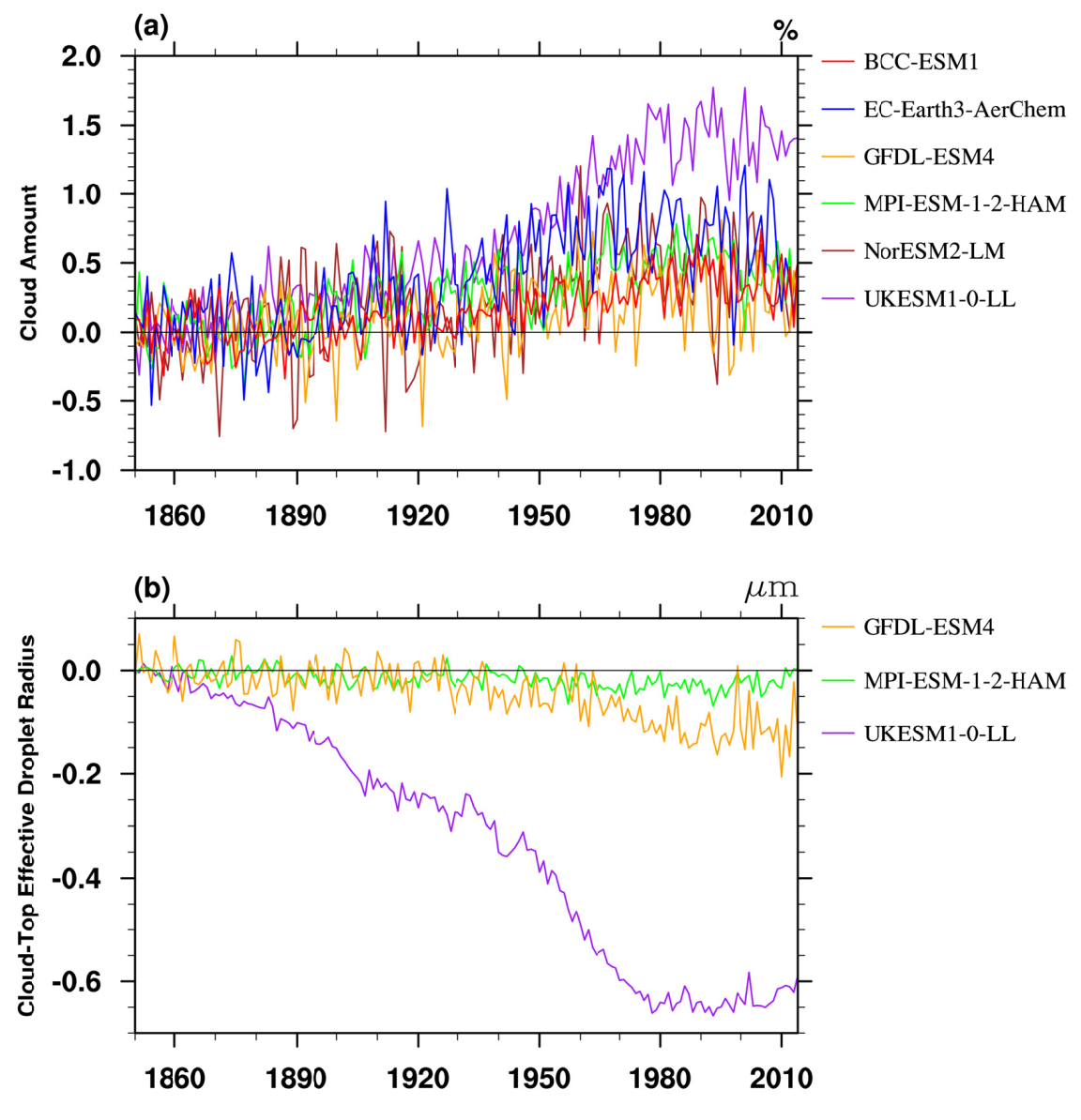
Figure 10 (a) Evolutions of global mean cloud amount differences between the historical and

hist-piAer simulations in MMMs, units: \%. (b) is the same as (a), but for cloud-top effective droplet radius $\left(r_{\text {eff }}, \mu \mathrm{m}\right)$. The $r_{\text {eff }}$ data is only available for GFDL-ESM4, MPI-ESM-1-2-HAM, and UKESM1-0-LL.

Figure 10 shows the evolution of global-mean differences in total cloud amount $(\Delta C L T)$ and cloud-top effective droplet radius $\left(\Delta \mathrm{r}_{\text {eff }}\right)$ between the historical and hist-piAer experiments. The $\triangle$ CLT and $\Delta \mathrm{r}_{\text {eff }}$ in UKESM1-0-LL are the largest and highly correlated with each other (with a correlation coefficient of -0.93). The $\Delta \mathrm{r}_{\text {eff }}$ and $\triangle \mathrm{CLT}$ are generally related to the radiative forcing part and adjustments part of ACI, respectively (Albrecht, 1989; Twomey, 1991). Therefore, the radiative forcing part and adjustments part of ACI may be closely coupled in UKESM1-0-LL and are hard to separate statistically. The strong correlation between cloud amount and $\mathrm{r}_{\text {eff }}$ response in UKESM1-0-LL indicates that this model is sensitivity to aerosol-cloud interactions, which is likely to contribute to it having the strongest aerosol-forcing-sensitivity of all the CMIP6 models in Fig.6b. approximate linear dependence of the differences between historical and hist-piAer simulations of cloudy part OSR (OSRcld_p) on cloud fraction in each ESM (parameter A in Fig.8g-8i). We call the degree of linear correlation of $\Delta$ OSRcld $\_$with $\Delta$ CLT the "cloud-amount term", and the residual will be referred to as the "cloud-albedo term". However, we reiterate that the so-called "cloud-amount term" may also include changes in the reflectivity of clouds if these are correlated with changes in cloud amount. Similarly, the cloud-albedo term will contain any sources of cloud amount changes which have not been removed by linearly regressing OSRcld_p against cloud amount. As such, we do not intend this nomenclature to indicate a precise separation of the radiative forcing part and adjustments part of ACI. Our decomposition allows first order assessment of these terms from historical simulations without the need for extra 
simulations or calls, and also allows estimates from observations and intermodel comparisons.

As described in the section 2.3 and the Appendix, the cloud-amount term is sensitive to two parameters: the cloud amount response (parameter $\mathrm{N}$ in Fig.8d-8f) and the sensitivity of OSR reflected from clouds to cloud amount changes (parameter A, Fig.8g-8i). As shown in Fig.9, UKESM1-0-LL has the largest contribution of the cloud-amount term to aerosol-forcing-sensitivity $\left(62 \%, 0.91 \mathrm{~W} \mathrm{mg}^{-1}\right)$; the cloud-amount term is the smallest in GFDL-ESM4 $\left(\sim 0.18 \mathrm{~W} \mathrm{mg}{ }^{-1}\right)$. The cloud-albedo term is defined to be linearly independent of cloud-amount changes (adjustments). For the CMIP6 ESMs, it can only be estimated as the residual after subtracting the cloud-amount term from the ACI. The cloud-albedo term is similar in BCC-ESM1, MPI-ESM-1-2-HAM, and NorESM2-LM. The inter-model variation for the cloud-amount term is about twice of that for the cloud-albedo term $(0.29 \mathrm{~W} / \mathrm{mg}$ V.s. $0.16 \mathrm{~W} / \mathrm{mg}$ ). That is, the variations of cloud-amount term are the major source of inter-model ACI (and the aerosol-forcing-sensitivity) differences between ESMs. Therefore, difference in the cloud-amount terms, across the ESMs, dominates the uncertainties in the aerosol-forcing-sensitivity.

Note that, neither do our definitions correspond to the effects measured by using multiple calls to the radiation scheme of a model, with and without aerosols, which measure instaneous radiative effects; multiple calls give a measure of the fast response of clouds to aerosol perturbations in a fixed thermodynamic and dynamical background, allowing for a clear separation between ACI and rapid adjustments (e.g., Bellouin et al., 2013). This differs from aerosol forcing diagnosed by differencing climate projections with different aerosol forcings, which include the slow effects of other feedbacks. For example, differences in climate forcings can lead to different SST patterns, which in turn alter the location and characteristics of clouds. Despite these differences, an advantage of our classification is that it provides a possible method for model evaluation since the variables used are also, in principle, available from the observations. 


\section{Conclusion}

This study focuses on the reproduction of historical surface air temperature anomalies in six CMIP6 ESMs. The ESMs systematically underestimate TAS anomalies relative to 1850 to 1900 in the NH midlatitudes, especially from 1960 to 1990, the "pot-hole" cooling (PHC) period. In the global mean, the excessive cooling in models is more pronounced at the surface, which is distinct from the response to greenhouse gases that preferentially heat the tropical upper troposphere. Previous studies suggested that aerosol cooling is too strong in many CMIP6 models. Our study more specifically found that the PHC is concurrent in time and space with anthropogenic $\mathrm{SO}_{2}$ emissions, which rapidly increase in the $\mathrm{PHC}$ period in $\mathrm{NH}$. The primary role of aerosol emissions in these biases is further supported by the differences between ESMs and the lower-complexity models. Differences between historical simulations and simulations with aerosol emissions fixed at their preindustrial levels (hist-piAer) are used to isolate the impacts of industrial aerosol emission. We propose that the overestimated aerosol concentrations and aerosol-forcing-sensitivity in the ESMs account for the spurious drop in TAS in the mid-twentieth century.

A large inter-model spread in the aerosol-forcing-sensitivity is evident between CMIP6 models. A simple metric is derived for determining the dominant contribution to the aerosol-forcing-sensitivity in any specific model. The ARI has a slight intra-model variation. The ACI accounts for more than $64 \%$ of the aerosol-forcing-sensitivity in all analyzed ESMs. The considerable inter-model variation in the aerosol-forcing-sensitivity is mainly attributable to the uncertainty in the ACI within models. The ACI can be further decomposed into a cloud-amount term and a cloud-albedo term. The cloud-amount term is found to be the major source of inter-model diversity of ACI.

Although the TAS anomaly is systematically underestimated in all ESMs, the reasons for the PHC are different among models. Therefore, different models require 

different improvement strategies. For example, modifying sulphate deposition processes may reduce the cold biases in EC-Earth3-AerChem, which has a relatively

610 large sulphate loadings; BCC-ESM1 has a relatively large proportion of ARI and may

611 need to focus on the effect of aerosol backscatter; the cloud-amount term (adjustments

612 part of ACI) contributes to more than $60 \%$ of the aerosol-forcing-sensitivity in 613 UKESM1-0-LL, which is comparable or even larger than the total 614 aerosol-forcing-sensitivity in the other ESMs. Considering the crucial role of cloud 615 properties on the inter-model spread in aerosol-forcing-sensitivity, the aerosol-cloud 616 interactions should be a focus in development of aerosol schemes within ESMs.

617 In this study, we mainly focus on the ESMs since all of them have the hist-piAer 618 experiment, which allows a simple way of diagnosing the sources of the anomalous cooling and estimates the aerosol-forcing-sensitivity. The method to estimate the aerosol-forcing-sensitivity can also be applied to the lower-complexity models.

621 Therefore, if the hist-piAer experiments were available for lower-complexity models,

622 it would be possible to isolate the contributions to aerosol-forcing-sensitivity that is due to the added aerosol complexity in the ESMs. 
626 Appendix: Decomposition of the Aerosol-radiation interaction and aerosol-cloud 627 interaction

Considering the dominate role of sulphate aerosol on anthropogenic aerosol forcing, we use the sulphate loading (loadSO4) as a proxy for all aerosol in our analysis. The aerosol-forcing-sensitivity (as determined by the difference between the historical and hist-piAer experiments) is estimated by the all-sky OSR differences per sulfate burden unit ( $\triangle \mathrm{OSR} / \Delta$ loadSO4) and it is the combination of OSR differences in the clear-sky parts ( $\Delta$ OSRclr $\_$p/ $\Delta$ loadSO4) and the cloudy parts ( $\Delta$ OSRcld $\_$/ $\Delta$ loadSO4):

$$
\Delta O S R / \Delta \text { loadSO4 }=\Delta \text { OSRclr } p / \Delta \text { loadSO4 }+\Delta \text { OSRcld } p / \Delta \text { loadSO4. }
$$
(A1)

The OSRclr_p for a particular experiment can be calculated as:

$$
\text { OSRclr } \_=(1-C L T / 100 .) * O S R c l r \text {, }
$$

where CLT is the total cloud amount (unit: \%), and OSRclr is the OSR assuming all clear sky (unit: $\mathrm{W} / \mathrm{m}^{2}$ ). The cloud amount changes $(\triangle C L T)$ will modify the propotion of clear-sky and then affect the OSR changes attributed to the clear-sky part by covering or uncovering aerosols in clear sky. Therefore, based on equation (A2), $\triangle \mathrm{OSR} c 1 \mathrm{p}$ / $/ \triangle$ loadSO4 can be decomposed into the OSRclr-response ( $\triangle O S R c l r / \Delta$ loadSO4) and CLT-response ( $\triangle C L T / \triangle$ loadSO4):

$$
\begin{aligned}
\Delta O S R c l r \_p / \Delta l o a d S O 4= & \left(1-C L T \_h i s t / 100 .\right) * \Delta O S R c l r / \Delta l o a d S O 4 \\
& -O S R c l r \_h i s t / 100 * \Delta C L T / \Delta \text { loadSO4+residual_clrp } \\
= & \left(1-C L T \_h i s t / 100 .\right) * M-O S R c l r \_h i s t / 100 * N+\text { residual_clrp },
\end{aligned}
$$

where CLT_hist and OSRclr_hist are the mean CLT and OSRclr in the historical experiment. Residual_clrp is the residual term that is non-linear in $\triangle$ OSRclr and $\triangle \mathrm{CLT}$. The parameter $\mathrm{M}=\Delta \mathrm{OSR}$ clr/ $\triangle$ loadSO4 is related to strength of aerosol-radiation interaction and can be estimated by linear fitting of $\triangle$ OSRclr on $\Delta$ loadSO4. The parameter $\mathrm{N}=\triangle C L T / \Delta$ loadSO4 is related to CLT-response and estimated by linear fitting of $\triangle \mathrm{CLT}$ on $\triangle$ loadSO4.

The OSRcld $\_p$ is the cloudy part of OSR, accounting for the difference between OSR and OSRclr_p. The cloudy part of the OSR differences ( $\Delta$ OSRcld_p) can be generally estimated as: 


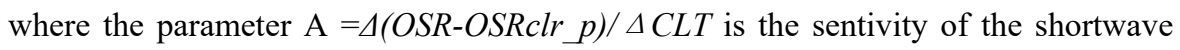
flux reflected by clouds to changes in cloud amount. The parameter A depends on the baseline cloud albedo (radiative flux per cloud amount unit) and can be estimated by linear fitting of $\Delta$ OSRcld $\_$on $\Delta$ CLT. Hence,

$$
\begin{aligned}
\Delta O S R c l d \_p / \Delta \text { loadSO4 } & =A * \Delta C L T / \Delta \text { loadSO4 }+ \text { cloud-albedo term } \\
& + \text { residual_cld }, \\
& =A * N+\text { cloud-albedo term }+ \text { residual_cld }
\end{aligned}
$$

where $\mathrm{N}$ is the parameter defined above. The cloud-albedo term on the right-hand side of equation (A4) can be obtained as a residual after subtracting $A^{*} N$ from $\triangle O S R c l d \_p /$ $\triangle$ loadSO4, thereby eliminating any linear dependence of the cloudy-sky shortwave flux response on cloud-amount changes.

As with the clear-sky decomposition, residual_cld is a possible non-linear term and is assumed to be small. This term cannot in fact be distinguished from the cloud-albedo term, in this analysis: we must therefore accept that cloud-albedo changes could be accompanied by non-linear changes in macroscopic cloud properties (in this framework).

The total aerosol-forcing-sensitivity can be measured by substituting the dervived values of $\triangle O S R / \triangle$ loadSO4 from both the clear sky (equation A3) and cloudy (equation A4) parts back into equation (A1):

$$
\begin{aligned}
\Delta O S R / \triangle l o a d S O 4= & \left(1-C L T \_h i s t / 100 .\right) * M-O S R c l r \_h i s t / 100 * N \\
& +A^{*} N+\text { cloud_albedo_term }+ \text { residual } \\
= & \left(1-C L T \_h i s t / 100\right) * M+\left(A-O S R c l r \_h i s t / 100 .\right) * N \\
& + \text { cloud_albedo_term }+ \text { residual_osr. }
\end{aligned}
$$

Based on equation (A5), the total aerosol-forcing-sensitivity can therefore be decomposed to the aerosol-radiation interaction term (ARI), (1-CLT_hist/100.)*M, cloud-amount term as (A - OSRclr_hist/100.)*N, and cloud-albedo term (defined as a residual). 
690 Data Availability. All the model data can be freely downloaded from the Earth System 691 Federation Grid (ESGF) nodes (https://esgf-node.llnl.gov/search/cmip6/). The global

692 historical surface temperature anomalies HadCRUT5 dataset is freely available on 693 https://www.metoffice.gov.uk/hadobs/hadcrut5/data/current/download.html.

\section{Author contributions}

696 The main ideas were formulated by JZ, KF, STT, JPM, and TW. JZ, KF, and STT wrote the original draft, and the results were supervised by LJW, BBB, and DS. All the authors discussed the results and contributed to the final manuscript.

\section{Competing interests}

The authors declare that they have no conflict of interest.

\section{Acknowledgments}

This work was supported by The National Key Research and Development Program of China (Grant no. 2018YFE0196000 and 2016YFA0602100). All the AUTHORS were supported by the UK-China Research \& Innovation Partnership Fund through the Met Office Climate Science for Service Partnership (CSSP) China as part of the 


\section{Reference}

Aas, W., Mortier, A., Bowersox, V., Cherian, R., Faluvegi, G., Fagerli, H., Hand, J., Klimont, Z., Galy-Lacaux, C., Lehmann, C. M. B., Myhre, C. L., Myhre, G., Olivie, D., Sato, K., Quaas, J., Rao, P. S. P., Schulz, M., Shindell, D., Skeie, R. B., Stein, A., Takemura, T., Tsyro, S., Vet, R., and Xu, X.: Global and regional trends of atmospheric sulfur (vol 9, 953, 2019), Scientific Reports, 10, 10.1038/s41598-020-62441-w, 2020.

ALBRECHT, B. A.: Aerosols, Cloud Microphysics, and Fractional Cloudiness, Science, 245, 1227-1230, 10.1126/science.245.4923.1227, 1989.

Bellouin, N., Mann, G. W., Woodhouse, M. T., Johnson, C., Carslaw, K. S., and Dalvi, M.: Impact of the modal aerosol scheme GLOMAP-mode on aerosol forcing in the Hadley Centre Global Environmental Model, Atmospheric Chemistry and Physics, 13, 3027-3044, 10.5194/acp-13-3027-2013, 2013.

Bethke, I., Wang, Y., Counillon, F., Kimmritz, M., Fransner, F., Samuelsen, A., Langehaug, H. R., Chiu, P.-G., Bentsen, M., Guo, C., Tjiputra, J., Kirkevåg, A., Oliviè, D. J. L., Seland, Ø., Fan, Y., Lawrence, P., Eldevik, T., and Keenlyside, N.: NCC NorCPM1 model output prepared for CMIP6 CMIP, Earth System Grid Federation [dataset], 10.22033/ESGF/CMIP6.10843, 2019.

Bindoff, N. L., Stott, P. A., AchutaRao, K. M., Allen, M. R., Gillett, N., Gutzler, D., Hansingo, K., Hegerl, G., et al.: Detection and Attribution of Climate Change: from Global to Regional, in: Climate Change 2013: The Physical Science Basis. Contribution of Working Group I to the Fifth Assessment Report of the Intergovernmental Panel on Climate Change [Stocker, T.F., D. Qin, G.-K. Plattner, M. Tignor, S.K. Allen, J. Boschung, A. Nauels, Y. Xia, V. Bex and P.M. Midgley (eds.)]. Cambridge University Press, Cambridge, United Kingdom and New York, NY, USA.

Charlson, R. J., Langner, J., and Rodhe, H.: Sulphate aerosol and climate, Nature, 348, 22-22, 10.1038/348022a0, 1990.

Collins, W., Lamarque, J.-F., Schulz, M., Boucher, O., Eyring, V., Hegglin, M., Maycock, A., Myhre, G., Prather, M., Shindell, D., and Smith, S.: AerChemMIP: Quantifying the effects of chemistry and aerosols in CMIP6, Geoscientific Model Development, 10, 585-607, 10.5194/gmd-10-585-2017, 2017.

Collins, W. J., Fry, M. M., Yu, H., Fuglestvedt, J. S., Shindell, D. T., and West, J. J.: Global and regional temperature-change potentials for near-term climate forcers, Atmospheric Chemistry and Physics, 13, 2471-2485, 10.5194/acp-13-2471-2013, 2013.

Dittus, A. J., Hawkins, E., Wilcox, L. J., Sutton, R. T., Smith, C. J., Andrews, M. B., and Forster, P. M.: Sensitivity of Historical Climate Simulations to Uncertain Aerosol Forcing, Geophysical Research Letters, 47, e2019GL085806, 10.1029/2019gl085806, 2020.

Döscher, R., Acosta, M., Alessandri, A., Anthoni, P., Arneth, A., Arsouze, T., Bergmann, T., Bernadello, R., Bousetta, S., Caron, L.-P., Carver, G., Castrillo, M., Catalano, F., Cvijanovic, I., Davini, P., Dekker, E., Doblas-Reyes, F. J., 
Docquier, D., Echevarria, P., Fladrich, U., Fuentes-Franco, R., Gröger, M., v. Hardenberg, J., Hieronymus, J., Karami, M. P., Keskinen, J.-P., Koenigk, T., Makkonen, R., Massonnet, F., Ménégoz, M., Miller, P. A., Moreno-Chamarro, E., Nieradzik, L., van Noije, T., Nolan, P., O’Donnell, D., Ollinaho, P., van den Oord, G., Ortega, P., Prims, O. T., Ramos, A., Reerink, T., Rousset, C., Ruprich-Robert, Y., Le Sager, P., Schmith, T., Schrödner, R., Serva, F., Sicardi, V., Sloth Madsen, M., Smith, B., Tian, T., Tourigny, E., Uotila, P., Vancoppenolle, M., Wang, S., Wårlind, D., Willén, U., Wyser, K., Yang, S., Yepes-Arbós, X., and Zhang, Q.: The EC-Earth3 Earth System Model for the Climate Model Intercomparison Project 6, Geosci. Model Dev. Discuss. [preprint], https://doi.org/10.5194/gmd-2020-446, in review, 2021.

Dunne, J. P., Horowitz, L. W., Adcroft, A. J., Ginoux, P., Held, I. M., John, J. G., Krasting, J. P., Malyshev, S., Naik, V., Paulot, F., Shevliakova, E., Stock, C. A., Zadeh, N., Balaji, V., Blanton, C., Dunne, K. A., Dupuis, C., Durachta, J., Dussin, R., Gauthier, P. P. G., Griffies, S. M., Guo, H., Hallberg, R. W., Harrison, M., He, J., Hurlin, W., McHugh, C., Menzel, R., Milly, P. C. D., Nikonov, S., Paynter, D. J., Ploshay, J., Radhakrishnan, A., Rand, K., Reichl, B. G., Robinson, T., Schwarzkopf, D. M., Sentman, L. T., Underwood, S., Vahlenkamp, H., Winton, M., Wittenberg, A. T., Wyman, B., Zeng, Y., and Zhao, M.: The GFDL Earth System Model Version 4.1 (GFDL-ESM 4.1): Overall Coupled Model Description and Simulation Characteristics, J. Adv. Model. Earth Syst., 12, 10.1029/2019ms002015, 2020.

Eyring, V., Bony, S., Meehl, G. A., Senior, C. A., Stevens, B., Stouffer, R. J., and Taylor, K. E.: Overview of the Coupled Model Intercomparison Project Phase 6 (CMIP6) experimental design and organization, Geosci. Model Dev., 9, 1937-1958, 10.5194/gmd-9-1937-2016, 2016.

Flynn, C. M. and Mauritsen, T.: On the climate sensitivity and historical warming evolution in recent coupled model ensembles, Atmos. Chem. Phys., 20, 7829-7842, 10.5194/acp-20-7829-2020, 2020.

Gillett, N. P., Shiogama, H., Funke, B., Hegerl, G., Knutti, R., Matthes, K., Santer, B. D., Stone, D., and Tebaldi, C.: The Detection and Attribution Model Intercomparison Project (DAMIP v1.0) contribution to CMIP6, Geosci. Model Dev., 9, 3685-3697, 10.5194/gmd-9-3685-2016, 2016.

Held, I. M., Guo, H., Adcroft, A., Dunne, J. P., Horowitz, L. W., Krasting, J., Shevliakova, E., Winton, M., Zhao, M., Bushuk, M., Wittenberg, A. T., Wyman, B., Xiang, B., Zhang, R., Anderson, W., Balaji, V., Donner, L., Dunne, K., Durachta, J., Gauthier, P. P. G., Ginoux, P., Golaz, J. C., Griffies, S. M., Hallberg, R., Harris, L., Harrison, M., Hurlin, W., John, J., Lin, P., Lin, S. J., Malyshev, S., Menzel, R., Milly, P. C. D., Ming, Y., Naik, V., Paynter, D., Paulot, F., Rammaswamy, V., Reichl, B., Robinson, T., Rosati, A., Seman, C., Silvers, L. G., Underwood, S., and Zadeh, N.: Structure and Performance of GFDL's CM4.0 Climate Model, J. Adv. Model. Earth Syst., 11, 3691-3727, 10.1029/2019ms001829, 2019.

Kennedy, J. J., Rayner, N. A., Atkinson, C. P., and Killick, R. E.: An Ensemble Data 
Set of Sea Surface Temperature Change From 1850: The Met Office Hadley Centre HadSST.4.0.0.0 Data Set, Journal of Geophysical Research-Atmospheres, 124, 7719-7763, 10.1029/2018jd029867, 2019.

Lohmann, U. and Feichter, J.: Global indirect aerosol effects: a review, Atmospheric Chemistry and Physics, 5, 715-737, 10.5194/acp-5-715-2005, 2005.

Manktelow, P. T., Mann, G. W., Carslaw, K. S., Spracklen, D. V., and Chipperfield, M. P.: Regional and global trends in sulfate aerosol since the 1980s, Geophysical Research Letters, 34, 10.1029/2006gl028668, 2007.

Mauritsen, T., Bader, J., Becker, T., Behrens, J., Bittner, M., Brokopf, R., Brovkin, V., Claussen, M., Crueger, T., Esch, M., Fast, I., Fiedler, S., Flaeschner, D., Gayler, V., Giorgetta, M., Goll, D. S., Haak, H., Hagemann, S., Hedemann, C., Hohenegger, C., Ilyina, T., Jahns, T., Jimenez-de-la-Cuesta, D., Jungclaus, J., Kleinen, T., Kloster, S., Kracher, D., Kinne, S., Kleberg, D., Lasslop, G., Kornblueh, L., Marotzke, J., Matei, D., Meraner, K., Mikolajewicz, U., Modali, K., Moebis, B., Muellner, W. A., Nabel, J. E. M. S., Nam, C. C. W., Notz, D., Nyawira, S.-S., Paulsen, H., Peters, K., Pincus, R., Pohlmann, H., Pongratz, J., Popp, M., Raddatz, T. J., Rast, S., Redler, R., Reick, C. H., Rohrschneider, T., Schemann, V., Schmidt, H., Schnur, R., Schulzweida, U., Six, K. D., Stein, L., Stemmler, I., Stevens, B., von Storch, J.-S., Tian, F., Voigt, A., Vrese, P., Wieners, K.-H., Wilkenskjeld, S., Winkler, A., and Roeckner, E.: Developments in the MPI-M Earth System Model version 1.2 (MPI-ESM1.2) and Its Response to Increasing CO2, J. Adv. Model. Earth Syst., 11, 998-1038, 10.1029/2018ms001400, 2019.

Meehl, G. A., Senior, C. A., Eyring, V., Flato, G., Lamarque, J.-F., Stouffer, R. J., Taylor, K. E., and Schlund, M.: Context for interpreting equilibrium climate sensitivity and transient climate response from the CMIP6 Earth system models, Science Advances, 6, 10.1126/sciadv.aba1981, 2020.

Mitchell, J. F. B., Johns, T. C., Gregory, J. M., and Tett, S. F. B.: Climate response to increasing levels of greenhouse gases and sulphate aerosols, Nature, 376, 501-504, 10.1038/376501a0, 1995.

Morice, C. P., Kennedy, J. J., Rayner, N. A., Winn, J. P., Hogan, E., Killick, R. E., Dunn, R. J. H., Osborn, T. J., Jones, P. D., and Simpson, I. R.: An Updated Assessment of Near-Surface Temperature Change From 1850: The HadCRUT5 Data Set, Journal of Geophysical Research-Atmospheres, 126, 10.1029/2019jd032361, 2021.

Myhre, G., D. Shindell, F.-M. Bréon, W. Collins, J. Fuglestvedt, J. Huang, D. Koch, J.-F. Lamarque, D. Lee, B. Mendoza, T. Nakajima, A. Robock, G. Stephens, T. Takemura and H. Zhang: Anthropogenic and Natural Radiative Forcing, in: Climate Change 2013: The Physical Science Basis. Contribution of Working Group I to the Fifth Assessment Report of the Intergovernmental Panel on Climate Change [Stocker, T.F., D. Qin, G.-K. Plattner, M. Tignor, S.K. Allen, J. Boschung, A. Nauels, Y. Xia, V. Bex and P.M. Midgley (eds.)]. Cambridge University Press, Cambridge, United Kingdom and New York, NY, USA.

Noije, T., Bergman, T., Sager, P., O'Donnell, D., Makkonen, R., Gonçalves-Ageitos, 
M., Döscher, R., Fladrich, U., Hardenberg, J., Keskinen, J.-P., Korhonen, H., Laakso, A., Myriokefalitakis, S., Ollinaho, P., Pérez García-Pando, C., Reerink, T., Schrödner, R., Wyser, K., and Yang, S.: EC-Earth3-AerChem, a global climate model with interactive aerosols and atmospheric chemistry participating in CMIP6, 10.5194/gmd-2020-413, 2020.

Osborn, T. J., Jones, P. D., Lister, D. H., Morice, C. P., Simpson, I. R., Winn, J. P., Hogan, E., and Harris, I. C.: Land Surface Air Temperature Variations Across the Globe Updated to 2019: The CRUTEM5 Data Set, Journal of Geophysical Research: Atmospheres, 126, e2019JD032352, https://doi.org/10.1029/2019JD032352, 2021.

Ramanathan, V. and Feng, Y.: Air Pollution, Greenhouse Gases and Climate Change: Global and Regional Perspectives, Atmospheric Environment, 43, 37-50, 10.1016/j.atmosenv.2008.09.063, 2009.

Seland, Ø., Bentsen, M., Olivié, D., Toniazzo, T., Gjermundsen, A., Graff, L. S., Debernard, J. B., Gupta, A. K., He, Y.-C., Kirkevåg, A., Schwinger, J., Tjiputra, J., Aas, K. S., Bethke, I., Fan, Y., Griesfeller, J., Grini, A., Guo, C., Ilicak, M., Karset, I. H. H., Landgren, O., Liakka, J., Moseid, K. O., Nummelin, A., Spensberger, C., Tang, H., Zhang, Z., Heinze, C., Iversen, T., and Schulz, M.: Overview of the Norwegian Earth System Model (NorESM2) and key climate response of CMIP6 DECK, historical, and scenario simulations, Geosci. Model Dev., 13, 6165-6200, https://doi.org/10.5194/gmd-13-6165-2020, 2020.

Sellar, A. A., Jones, C. G., Mulcahy, J. P., Tang, Y., Yool, A., Wiltshire, A., O'Connor, F. M., Stringer, M., Hill, R., Palmieri, J., Woodward, S., de Mora, L., Kuhlbrodt, T., Rumbold, S. T., Kelley, D. I., Ellis, R., Johnson, C. E., Walton, J., Abraham, N. L., Andrews, M. B., Andrews, T., Archibald, A. T., Berthou, S., Burke, E., Blockley, E., Carslaw, K., Dalvi, M., Edwards, J., Folberth, G. A., Gedney, N., Griffiths, P. T., Harper, A. B., Hendry, M. A., Hewitt, A. J., Johnson, B., Jones, A., Jones, C. D., Keeble, J., Liddicoat, S., Morgenstern, O., Parker, R. J., Predoi, V., Robertson, E., Siahaan, A., Smith, R. S., Swaminathan, R., Woodhouse, M. T., Zeng, G., and Zerroukat, M.: UKESM1: Description and Evaluation of the UK Earth System Model, J. Adv. Model. Earth Syst., 11, 4513-4558, 10.1029/2019ms001739, 2019.

Shindell, D. and Faluvegi, G.: Climate response to regional radiative forcing during the twentieth century, Nat. Geosci., 2, 294-300, 10.1038/ngeo473, 2009.

Stevens, B., Fiedler, S., Kinne, S., Peters, K., Rast, S., Muesse, J., Smith, S. J., and Mauritsen, T.: MACv2-SP: a parameterization of anthropogenic aerosol optical properties and an associated Twomey effect for use in CMIP6, Geoscientific Model Development, 10, 433-452, 10.5194/gmd-10-433-2017, 2017.

Thorne, P. W., Lanzante, J. R., Peterson, T. C., Seidel, D. J., and Shine, K. P.: Tropospheric temperature trends: history of an ongoing controversy, Wiley Interdisciplinary Reviews-Climate Change, 2, 66-88, 10.1002/wcc.80, 2011.

Weart, S.: The Discovery of Global Warming, Bibliovault OAI Repository, the University of Chicago Press, 9, 10.2307/3986102, 2008.

Wilcox, L. J., Highwood, E. J., and Dunstone, N. J.: The influence of anthropogenic 
aerosol on multi-decadal variations of historical global climate, Environmental Research Letters, 8, 10.1088/1748-9326/8/2/024033, 2013.

Wilcox, L. J., Highwood, E. J., Booth, B. B. B., and Carslaw, K. S.: Quantifying sources of inter-model diversity in the cloud albedo effect, Geophysical Research Letters, 42, 1568-1575, 10.1002/2015g1063301, 2015.

Williams, K., Copsey, D., Blockley, E., Bodas-Salcedo, A., Calvert, D., Comer, R., Davis, P., Graham, T., Hewitt, H., Hill, R., Hyder, P., Ineson, S., Johns, T., Keen, B., Lee, R., Megann, A., Milton, S., Rae, J., Roberts, M., and Xavier, P.: The Met Office Global Coupled Model 3.0 and 3.1 (GC3.0 and GC3.1) Configurations, J. Adv. Model. Earth Syst., 10, 10.1002/2017MS001115, 2017.

Wu, P., Christidis, N., and Stott, P.: Anthropogenic impact on Earth's hydrological cycle, Nature Climate Change, 3, 807-810, 10.1038/nclimate1932, 2013.

Wu, T., Hu, A., Gao, F., Zhang, J., and Meehl, G.: New insights into natural variability and anthropogenic forcing of global/regional climate evolution, npj Climate and Atmospheric Science, 2, 10.1038/s41612-019-0075-7, 2019a.

Wu, T., Zhang, F., Zhang, J., Jie, W., Zhang, Y., Wu, F., Li, L., Yan, J., Liu, X., Lu, X., Tan, H., Zhang, L., Wang, J., and Hu, A.: Beijing Climate Center Earth System Model version 1 (BCC-ESM1): model description and evaluation of aerosol simulations, Geosci. Model Dev., 13, 977-1005, 10.5194/gmd-13-977-2020, 2020.

Wu, T., Lu, Y., Fang, Y., Xin, X., Li, L., Li, W., Jie, W., Zhang, J., Liu, Y., Zhang, L., Zhang, F., Zhang, Y., Wu, F., Li, J., Chu, M., Wang, Z., Shi, X., Liu, X., Wei, M., Huang, A., Zhang, Y., and Liu, X.: The Beijing Climate Center Climate System Model (BCC-CSM): the main progress from CMIP5 to CMIP6, Geosci. Model Dev., 12, 1573-1600, 10.5194/gmd-12-1573-2019, 2019 b.

Yool, A., Palmieri, J., Jones, C. G., Sellar, A. A., de Mora, L., Kuhlbrodt, T., Popova, E. E., Mulcahy, J. P., Wiltshire, A., Rumbold, S. T., Stringer, M., Hill, R. S. R., Tang, Y., Walton, J., Blaker, A., Nurser, A. J. G., Coward, A. C., Hirschi, J., Woodward, S., Kelley, D. I., Ellis, R., and Rumbold-Jones, S.: Spin-up of UK Earth System Model 1 (UKESM1) for CMIP6, J. Adv. Model. Earth Syst., 12, 10.1029/2019ms001933, 2020.

Zhang, J., Wu, T., Zhang, F., Furtado, K., Xin, X., Shi, X., Li, J., Chu, M., Zhang, L., Liu, Q., Yan, J., Wei, M., and Ma, Q.: BCC-ESM1 Model Datasets for the CMIP6 Aerosol Chemistry Model Intercomparison Project (AerChemMIP), Advances in Atmospheric Sciences, 38, 317-328, 10.1007/s00376-020-0151-2, 2021. 